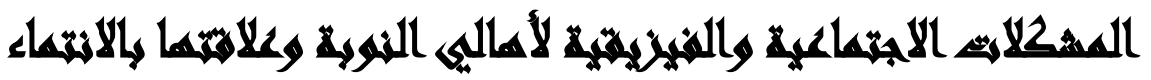

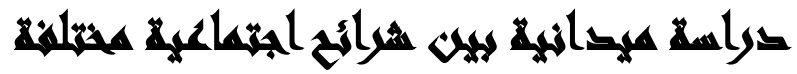

$[\uparrow]$

حاتم عبد المنعم أحمد(')- جمال شفيق أحمد(؟)- أمال محمد عبد العزيز

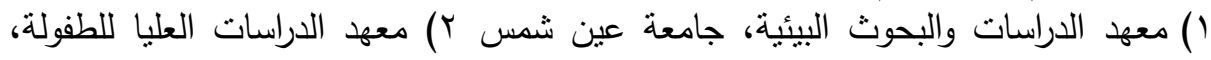

جامعة عين شمس الات

\section{المستخليه}

تهدف الدراسة الحالية إلى الكثف عن المشكلات الاجتماعية والفيزيقية لأهالى النوبة

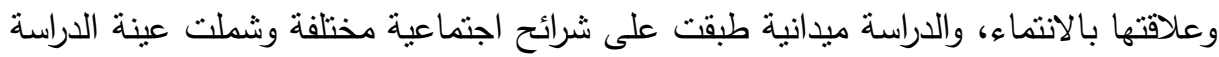

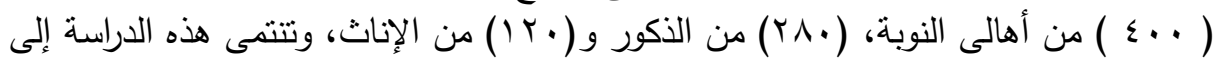

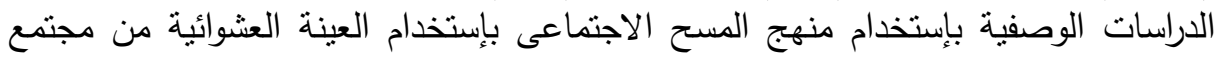

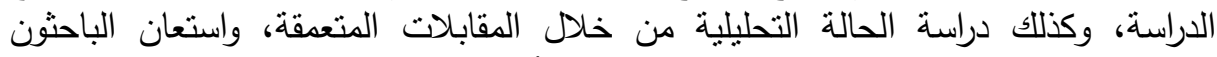

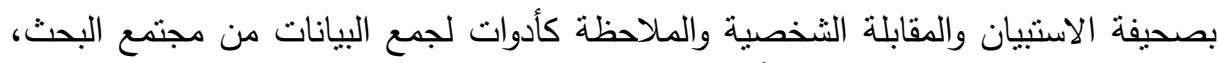

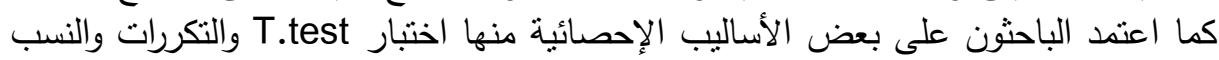

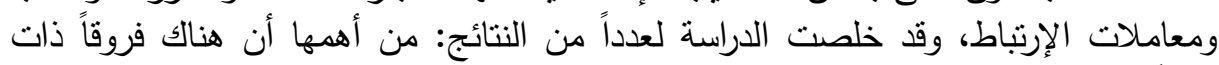

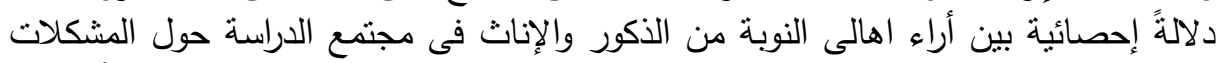

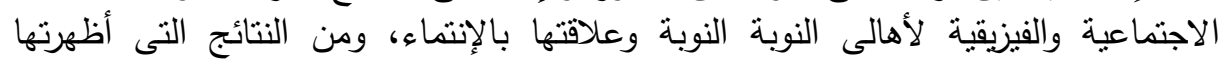

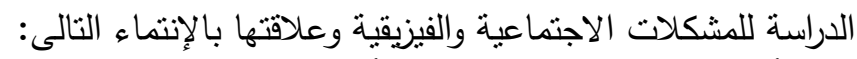

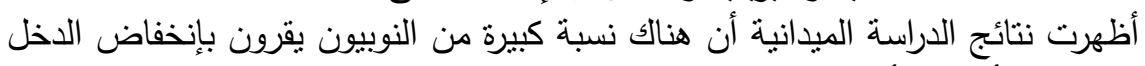

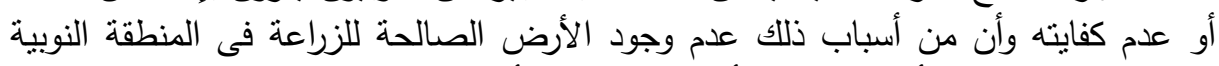

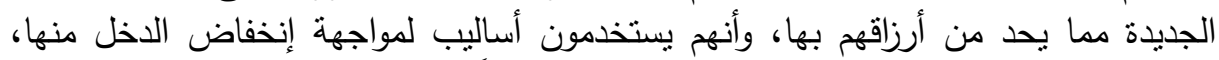

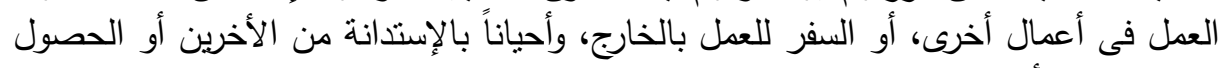

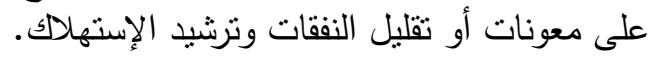

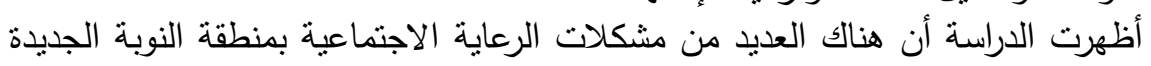

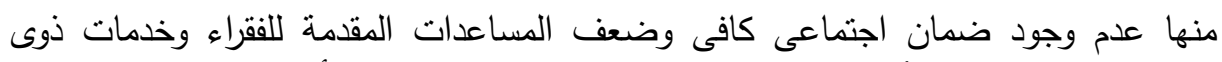

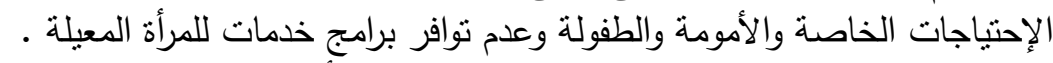

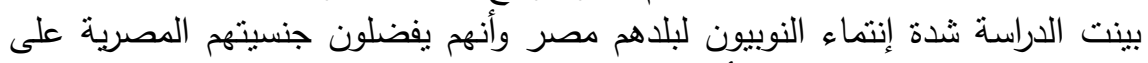

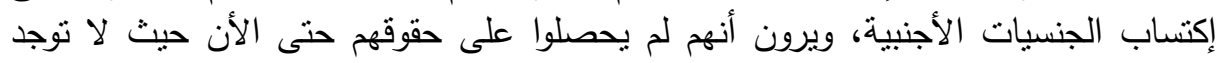
مساواة فى الحقوق والفرص داخل المجتمع المصرى من وجهة نظرهم.

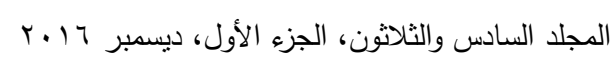


بينت الدراسة أن هناك شعور بين النوبيون بأنهم تعرضوا لظلم تاريخى من الأنظمة

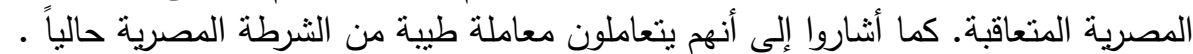

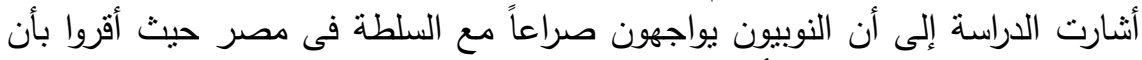
التهجير مثل لهم ظلم تاريخى. وأوصت الدراسة المسؤليين الحكوميين بيحث نلأك المشاكل وحلها فى أسرع وقت.

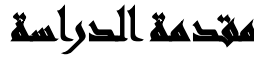

بدأت المشكلات الاجتماعية لبلاد النوبة مع مطلع القرن العشرين وبالتحديد بعد إنشاء

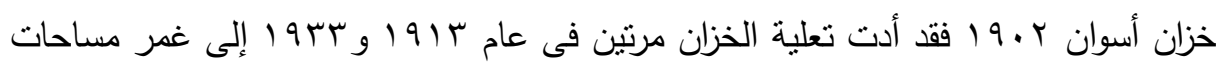

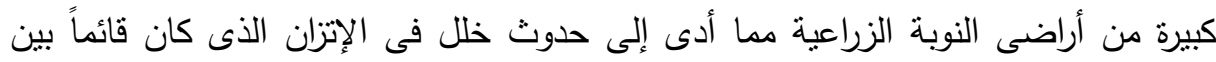

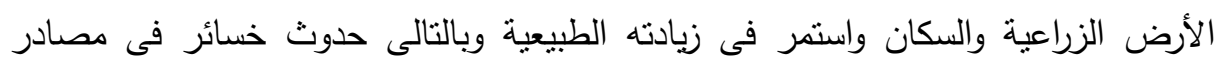
الدخل للنوبيين ثم جاء مشروع السد العالى كثانى المشروعات القومية لضبط التباتيه النيل والأمن

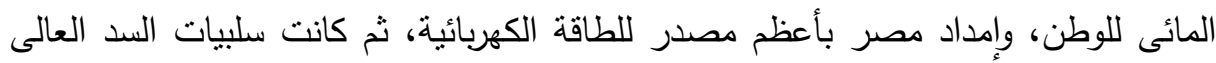
أنه أدى إلى غرق بلاد النوبة القديمة بما تحوى من أراض زراعية وقرى وندئ ونخيل وتراث ألاف

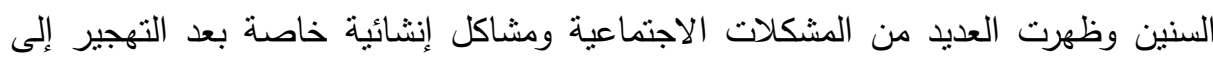
الأماكن الجديدة فى مدينة كوم إمبو ومنطقة نصر النوبة وبالنالى عدم التعاون فى مشروع التهجير وعدم تكيف الأهالى مع المشروع وجرح الخصوصية وعدم ملائمة تصميمات المساكن

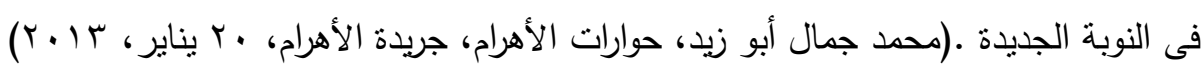

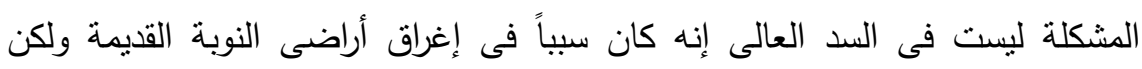

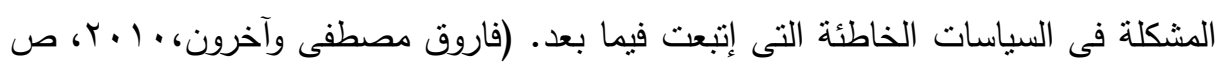

من هنا سيتم فى هذه الدراسة بحث المشكلات الاجتماعية والفيزيقية لأهالي النوبة

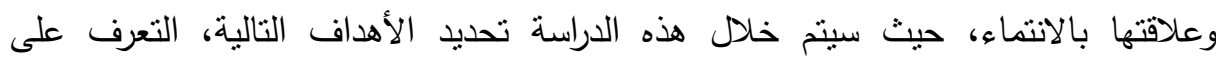
المشكلات الاجتماعية والمشكلات الفيزيقية لأهالي النوبة، التعرف على على علاقة المشكلات الاجتماعبة لأهالي النوبة بالإنتماء، التعرف على علاقة المشكلات الفيزيقية لأهالي النوبة 
بالانتماء، محاولة وضع تصور للحد من المشكلات الاجتماعية والفيزيقية لأهالي النوبة مستقبلاً، وستتفرع من هذه الأهداف عدة نساؤلات تبحث عن إجابات من أجل معرفة تلاك

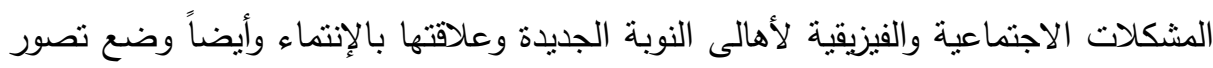

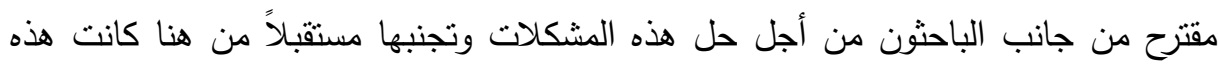

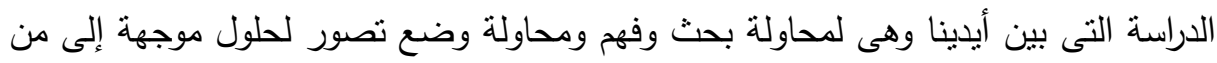
يعنيهم الأمر حتى نحد أو نخف لئ من هذه الشيكلات.

\section{هم:حلة التراسما}

زاد الاهتمام بدراسة المشكلات الاجتماعية نتيجة زيادة الاهتمام بدراسة مشكلات الإنسان

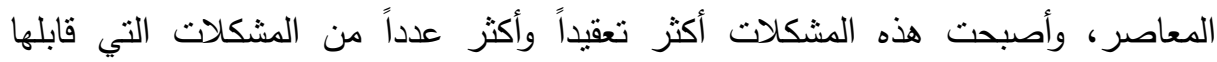

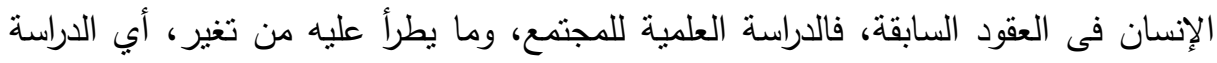

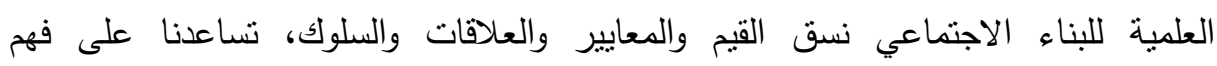
المشكلات المعاصرة فهماً أفضل. وقد سعى الإنسان إلى المنهج العلمي لتفسير الأثياء (الظواهر) التي يعجز عن فهمها لتبرير مخاوفه وتخفيف قلقة ولزيادة فهمه عن أحوال العالم الذي حوله وتقليل المصاعب التي يعاني منها، وتمهيد الطريق لرسم سياسة اجتماعية واضحة

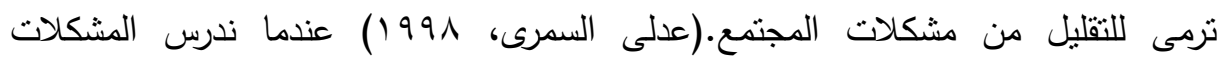
الاجتماعية في ضوء علاقاتها بالبناء الاجتماعي، فمن الصعب أن ندرس المشكلة الاجتماعية

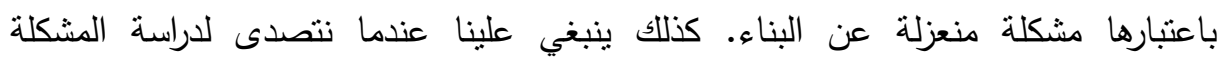
الاجتماعية، أن نعى أن المشكلات الاجتماعية ليست نبته شيطانية فجائية توجد فجأة وتختفي لئناهي

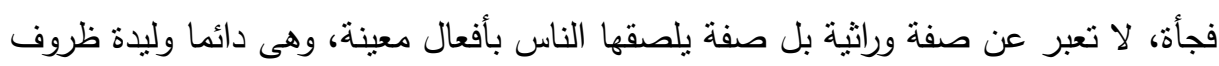
اجتماعية محددة ومحصلة إخفاق الناس من تحقيق أهدافهم وحاجاتهم نتيجة تعقد البناء الاجتماعي، فعندما تتعثر الجماعات عن التوافق مع التغيير تعجز عن تحقيق مطالبها

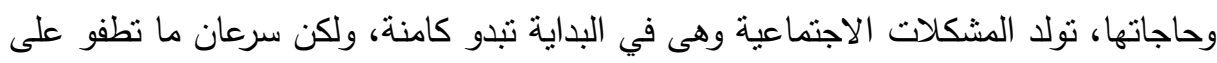

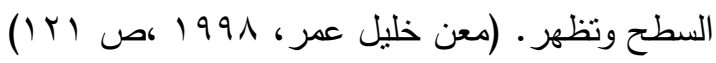

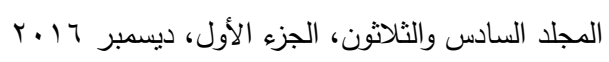


أن تهجير أهالى النوبة إلى مناطق صحراوية ليست على النيل والتعويض عن الأرض

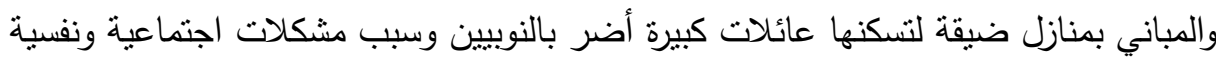
عديدة وعزلة جغرافية أضرت بالثقافة والتراث والعادات والتقاليد النوبية. ( فاروق مصطفى ولئل

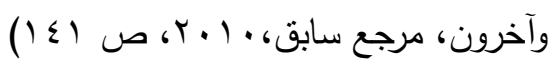

يعد الانتماء بمثابة اتجاه قوى يحركه دافع أقوى لإشباع حاجة أساسية لدى الإنسان يقهر

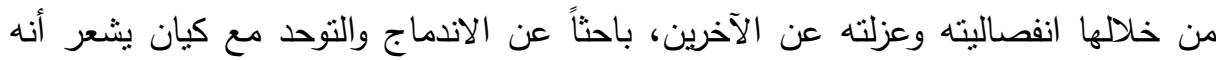
أكبر وأثمل وأقوى منه، ويبحث عن الأمان عن طريق تحقيق ذاته مع آخرين يكون مقبولاً

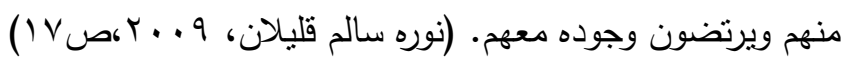

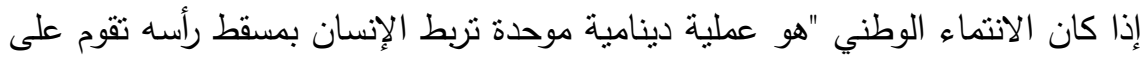
الوعى بظروف بلده واتجاهاتها السياسية والاقتصادية والاجتماعية، والالتزام بمتطلباتها، فيسمو الفرد بوطنه ويضحى بنفسه من أجل حمايته، فإن ضعف هذا الانتماء يعنى عدم ارتباط

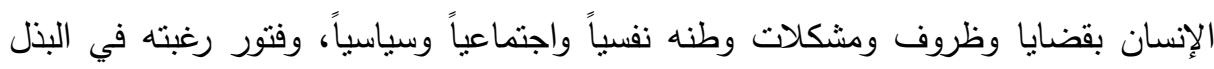

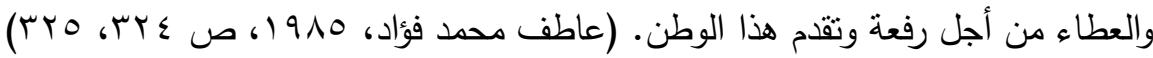
ويمكن تحديد مشكلة الدراسة الحالية من خلال عدة مؤشرات ومحاور وهى الهى" الصعوبات والمشكلات الاجتماعية والاقتصادية والسياسية التي تواجه أهالي النوبة وتؤثر على التئن ارتباطهم

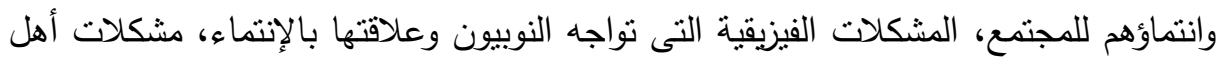
النوبة مع الأمن، مشكلات النوبة مع الإدارة المصرية، المشكلات المتعلقة بالمشاركة الاجتماعية والسياسية، الصراعات والمشكلات مع النظام السياسي، مدى ارتباط النوبيون بوطنهم الذي يعيشون فيه وإحساسهم بعلاقة إيجابية مع الوطن، مدى تفضيل مصلحة الوطن

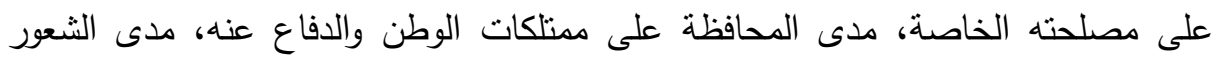

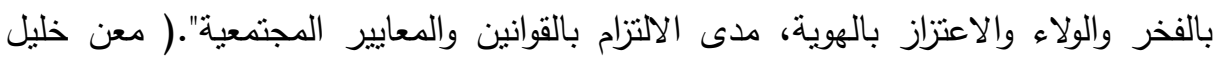


وبرجع اختيار منطقة النوبة في أسوان أن تلك البقعة من أراضي مصر قد تعرضت أكثر

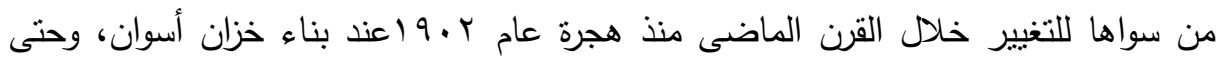
تهجيرهم الرابع عام بـ 197 إلى صحراء مصر في وادي كوم امبو الذي يعد منطقة غير مؤهلة لإقامة أى مجتمعات سكانية.

من هنا كانت المشكلة الرئيسية للدراسة التى تتحدد في الإجابة على تساؤل رئيسى فحواه

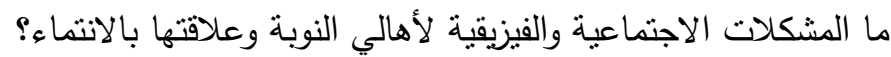

\section{تساؤلايت الكرواسلا}

تحاول الدراسة الإجابة على تساؤل رئيسى هو ما الشكلات الاجتماعية والفيزيقية

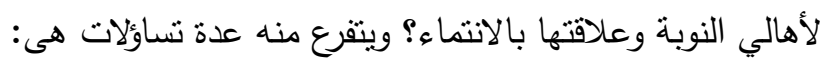

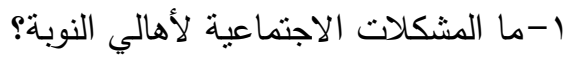
r-ما المشكلات الفيزيقية لأهالي النوبة؟

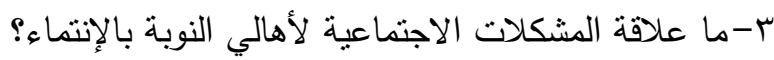

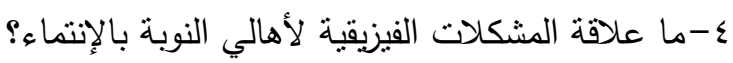

\section{هزوضن القواسمة}

1- هناك فروقاً ذات دلالة إحصائية بين الذكور والإناث لروئيته هذه المشكلات الاجتماعية r- هناك فروقاً ذات دلالة إحصائية بين الذكور والإناث لروئيتهم هذه المشكلات الفيزيقية لينة r- هناك فروقاً ذات دلالة إحصائية بين الذكور والإناث لرؤيتهم لعلاقة هذه المشكلات الاجتماعبة بالإنتماء ع- هناك فروقاً ذات دلالة إحصائية بين الذكور والإناث لرؤيتهم لعلاقة هذه المشكلات الفيزيقية بالإنتماء 


\section{أهمية الصواسمة}

تستمد الدراسة أهميتها من عدة عناصر هى:

أ. الأهمية العلمبةه:

- البحث عن المشكلات الاجتماعية والفيزيقية لأهالى النوبة وعلاقتها بالانتماء في الوقت الحالي.

- تحديد أهم التصورات والمقترحات امام متخذى القرار بالنسبة لوجود الحلول الممكنة لهذه المشكلات من عدمه.

\section{ب.الأهمية المجتمعية:}

- تتوع المشكلات وإختلاف معدلاتها هى ظاهرة جديرة بالدراسة والبحث لرسم صور واضحة المعالم عن المشكلات الاجتماعية والفيزيقية لأهالى النوبة وعلاقتها بالانتماء. - المشكلات الاجتماعية والفيزيقية وغيرها التى تقابل أهالى النوبة فى بيئاتهم الخارجية والتى • تؤثر على إنتمائهم للوطن

\section{أهساهيت التراسة}

تهدف الدراسة إلى "التعرف على المشكلات الاجتماعية والفيزيقية لأهالي النوبة وعلاقتها بالانتماء، ويتفرع منه عدة أهداف هیى: ا ـ التعرف على المشكلات الاجتماعية لأهالي النوبة. r. التعرف على المشكلات الفيزيقية لأهالي النوبة. r. التعرف على علاقة المشكلات الاجتماعية لأهالي النوبة بالانتماء. ء. التعرف على علاقة المشكلات الفيزيقية لأهالي النوبة بالانتماء. 0. محاولة وضع تصور للحد من المشكلات الاجتماعية والفيزيقية لأهالي النوبة. 


\section{همخاهيه السراسمة}

) المشكلة الاجتماعية: (Social Problem ): وتعرف المشكلة إصطلاحاً : بأنها

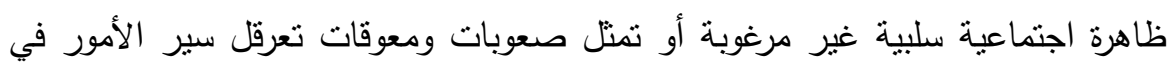

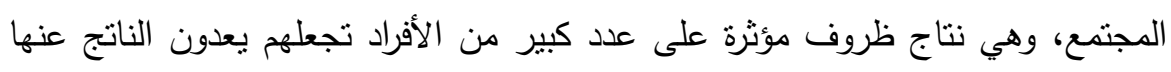

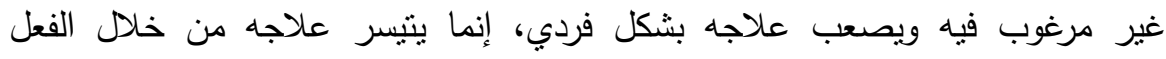
الاجتماعي الجمعي. وهناك من ينظر إلى المشكلات الاجتماعية والظواهر الاجتماعية Social issues ولى أنها جميعاً مترادفات

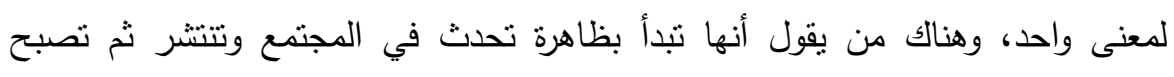

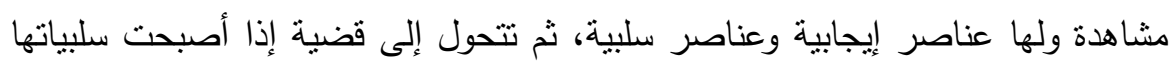

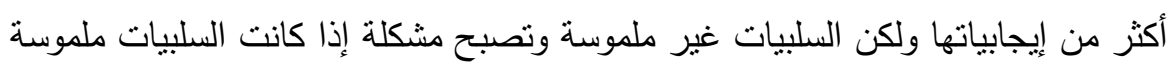

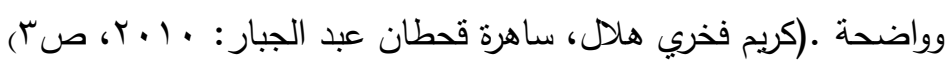

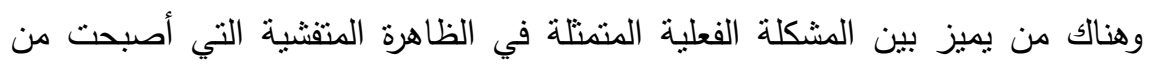

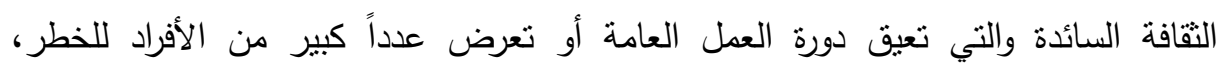

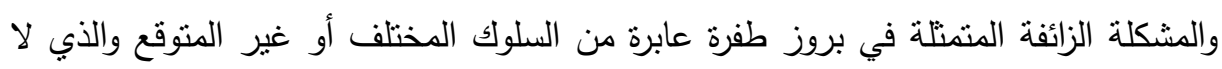

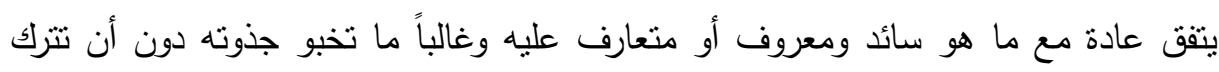
آثاراً تذكر في بنية القيم الفعالة في الثقافة المجتمعية.

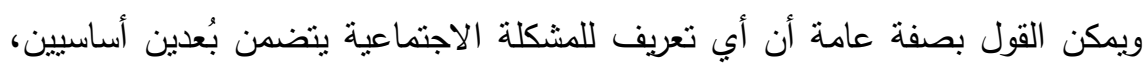

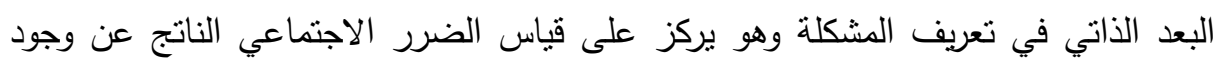

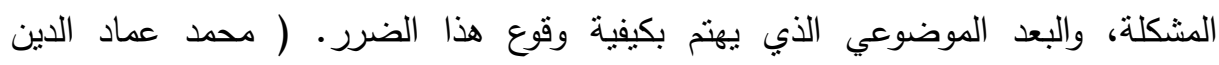

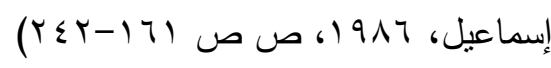

على الرغم من اتفاق علماء الاجتماع على أهمية دراسة الشكلات الاجتماعية، وفي

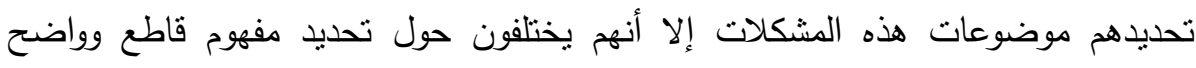

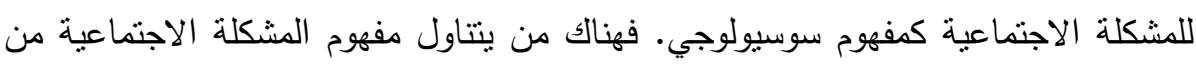
خلال معيار الذاتية أو الموضوعية له، وهناك من يحدد المشكلة الاجتماعية من خلال

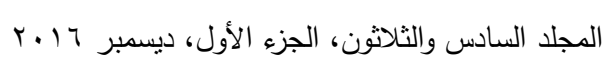


مستوياتها المختلفة، وثالث ينظر للمشكلات الاجتماعية في ضوء الشروط الواجب توافرها في

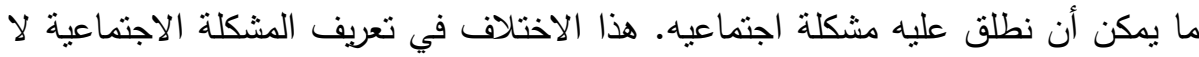

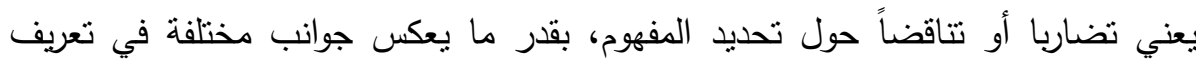

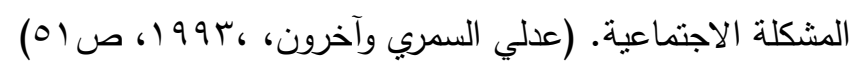

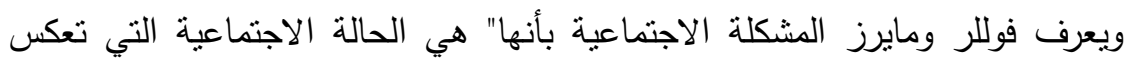

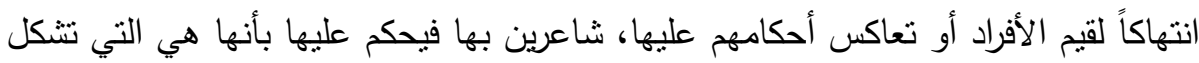

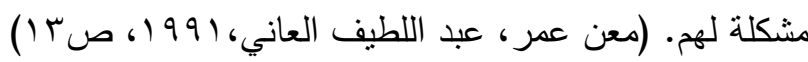
ويذهب روبرتسون Robertson في تعريف المشكلة الاجتماعية"إلى أنها تمنل فجوة غير مرغوبة بين المثاليات الاجتماعية المرغوبة والوقائع الاجتماعية الكائنة، فالمشكلة

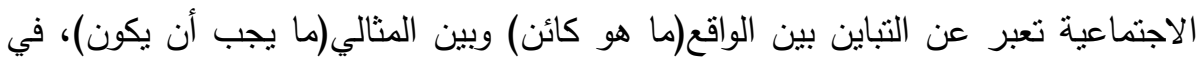

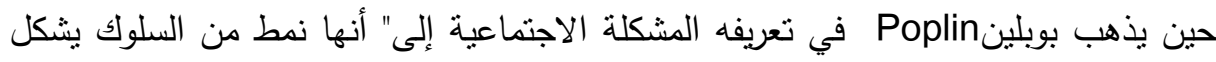

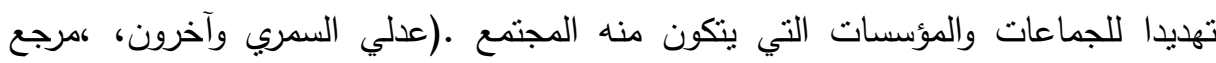

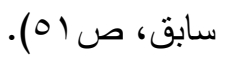
في حين تعرفها قناوي بأنها " تعبير عن انتشار أنماط سلوكية سلبية، ضارة بالمجتمع،

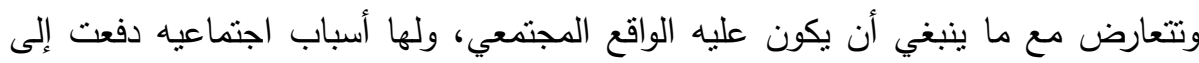

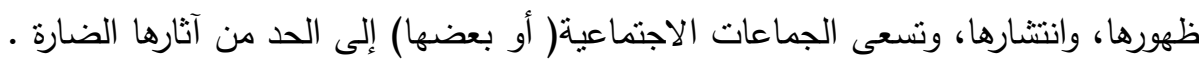

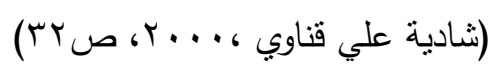
ويرى زهران أن الشكلات الاجتماعية تتمثل في نقص القدرة والارتباك في المسائل والمواقف الاجتماعية، والخوف من ارتكاب الأخطاء الاجتماعية، والخوف من مقابلة الناس،

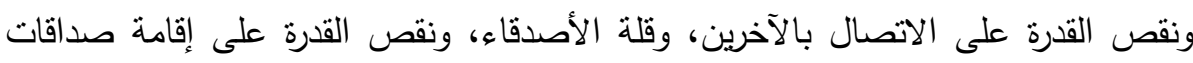

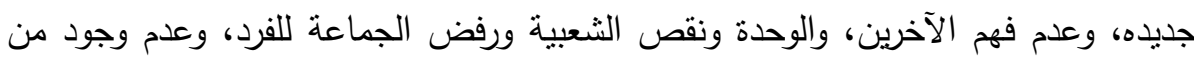

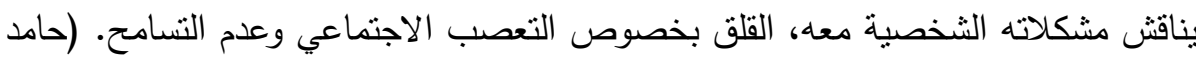

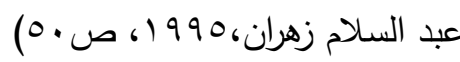


وتتحدد المشكلات الاجتماعية إجرائياً لأهالى النوبة بأنها: انخفاض الدخل وعدم كفايته،

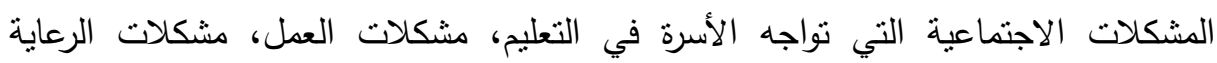

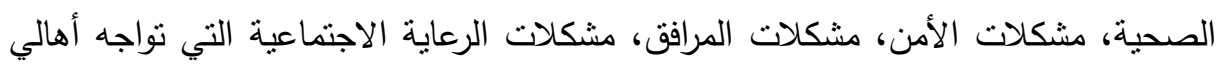
النوبة، وتؤثر على ارتباطهم وانتماؤهم للمجتمع.

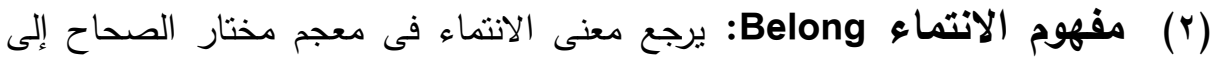

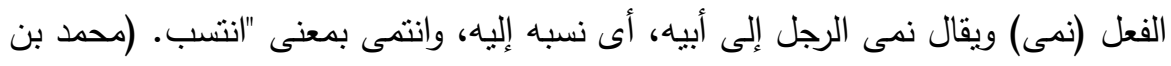

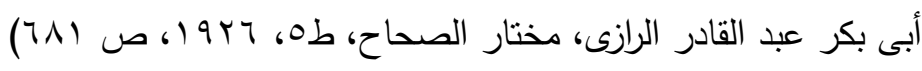

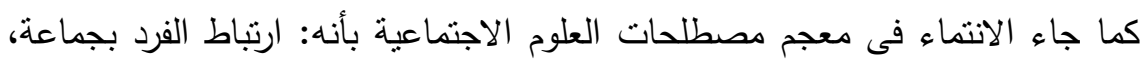

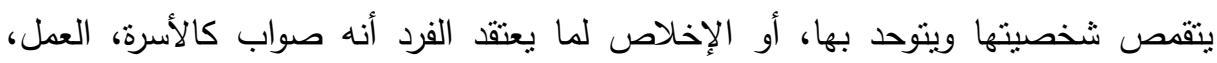

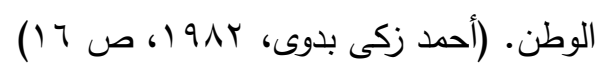
وورد فى المعجم الثنامل لمصطلحات علم النفس بأنه اتجاهاً بستشعره الفرد من خلال اندماجه فى جماعة وتوحده بها، وأنه صار جزءاً مقبولاً منها وله مكانته المتميزة ووضعه الآمن النه

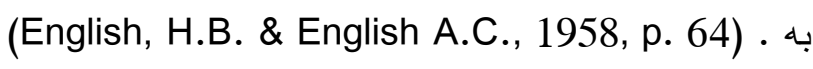
الانتماء حاجة نفسية طبيعية لاى الفرد ولكنها لاتحقق تلقائيا وفي كل الظروف ـ كما أنها لاتتخذ نمطاً سلوكياً واحدا للتعبير عن نفسها، بل نتعدد تلك الأنماط انساعاً وضيقا.

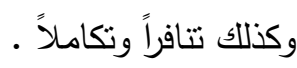
الانتماء إحساس وشعور وإدراك نفسي اجتماعي يترجم في شكل من أثنكال السلوك

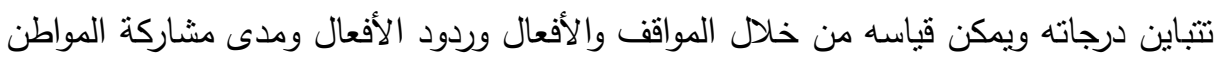
أو عزوفه ومدى التعاون أو الصراع ومدى الالتزام بالسلوك السوى أوالانحراف إلى السلوك

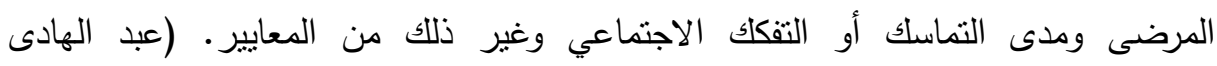

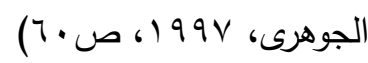
يُعرف الانتماء بأنه النزعة التي تذفع الفرد للاخول في إطار اجتماعي فكري معين بما

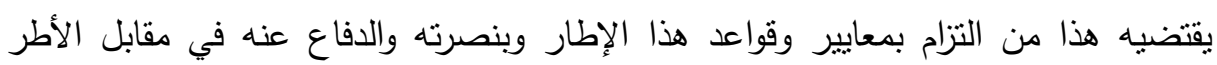

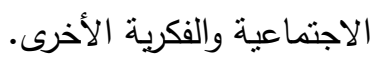

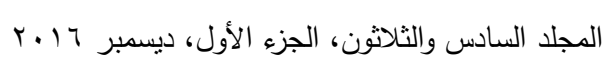


ويري البعض أن الانتماء هو حاجة اجتماعية والحاجة إلى الانتماء من العوامل التي

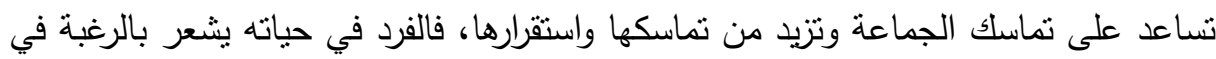

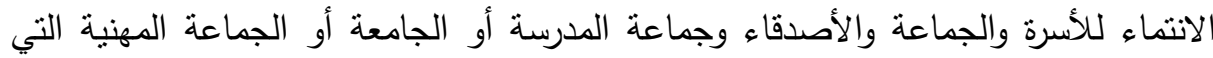
ينتمي أعضائها إلي مهنة معينة كما يرى البعض وأن روح الآنتماء تتكون من خلال ما يلي:

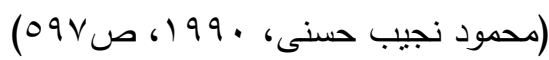
1-سعي الفرد وحركته لإشباع احتياجاته.

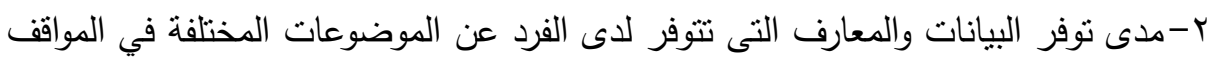
المختلفة.

r- الجماعات التي ينتمى إليها ويتفاعل معها متل الأسرة وجماعة العمل أو الجماعة المهنية. ع-نسق شخصية الفرد وتكوينه النفسي .

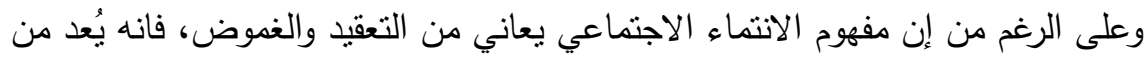

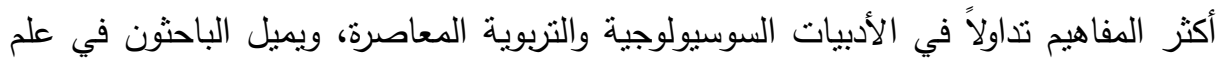
الاجتماع إلى تحديد الانتماء الاجتماعي للفرد وفقاً لمعيارين أساسيين متكاملين هما: العامل

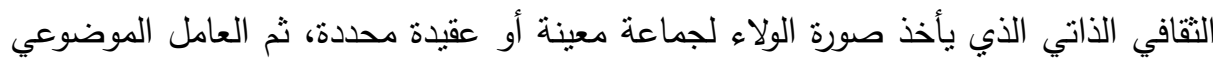
الذي يتمثل في معطيات الواقع الاجتماعي الذي يحيط بالفرد أي الانتماء الفعلي للفرد أو أولاءول

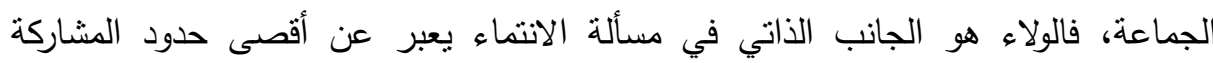

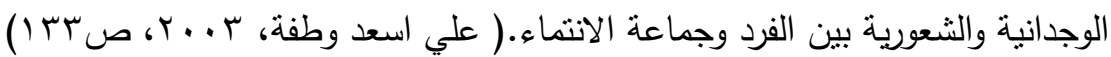

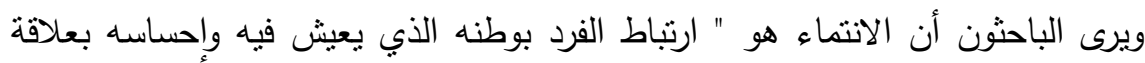

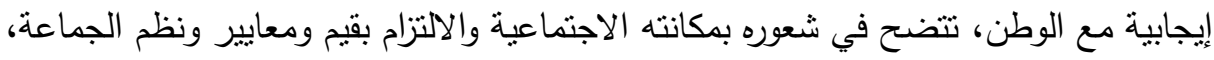
وتفضيل مصلحة الوطن على مصلحته الخاصة ،والمحافظة على ممتلكات الوطن الذي ينتمي

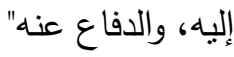




\section{السوراساهي الماريخة}

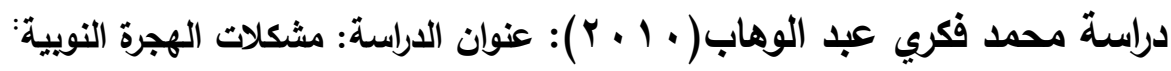

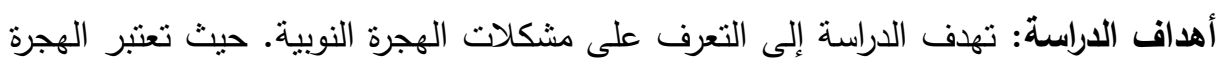
الحالية وإعادة توطين سكان النوبة واحدة من أهم الأحداث من نوعها في تاريخ الجمهورية الكانية

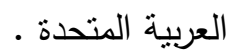

نتائج الاراسة: نوصلت الدراسة لعدة نتائج أهمها: 1. عند وصول النوبيين إلى مواطنهم الجديدة كانوا في غاية السعادة لكفاوة استقبال السلطات

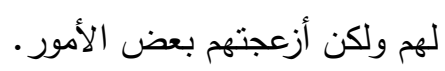

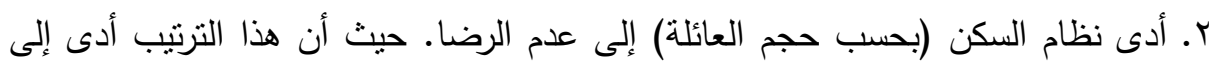

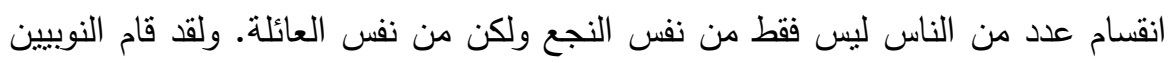

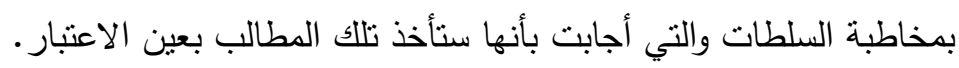

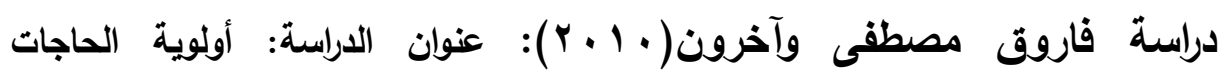

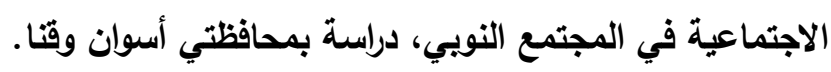

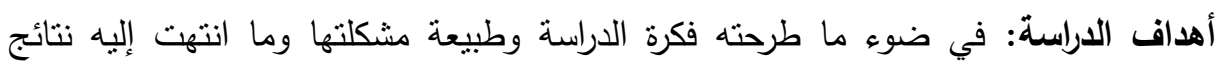

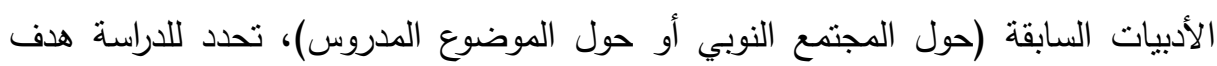

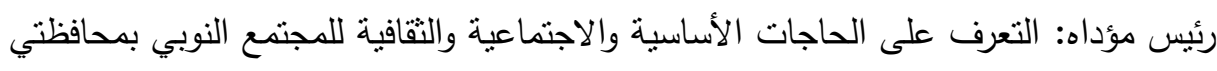
أسوان وقنا، وأولوية هذه الحاجات لاى النوري النوبيين أنفسهم. نتائج الدراسة: توصلت الدراسة إلى نتائج من أهمها:

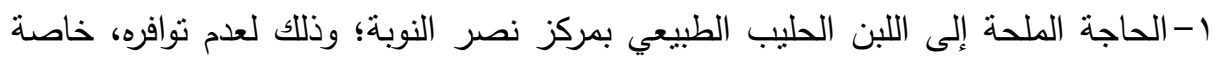

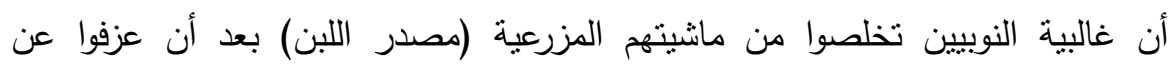
الزراعة، وقاموا بتأجير أراضيهم أو إعطائها بالمزارعة أو المشاركة لآخرين من أبناء البناء الصعيد. - (الصنا. ץ- الحاجة إلى اللبن المجفف بسعر مدعم، لارتفاع أسعاره، وعدم توافره بمنطقتي الدراسة مما

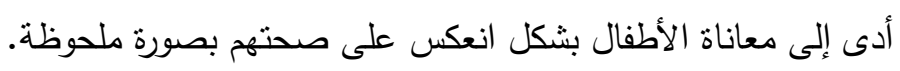

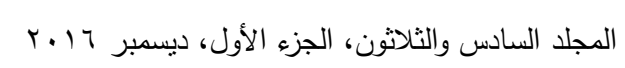


r-الحاجة إلى مستودعات تغطي التجمعات النوبية المختلفة؛ لسد العجز الواضح في أنابيب

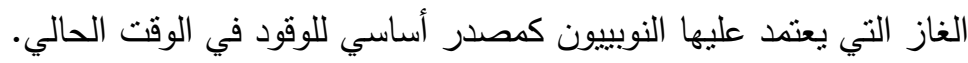

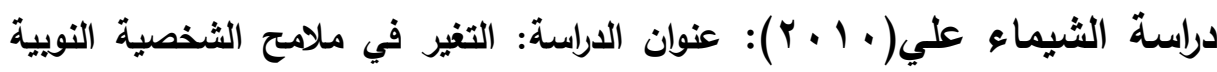
دراسة على عينة من النوبيين المقيمين في القاهرة الكبرى.

أهداف الاراسة: التعرف على بعض سمات وخصائص الثخصية النوبية المعاصرة في رؤيتها

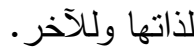

نتائج الدراسة: توصلت الدراسة لعدة نتائج من أهمها:

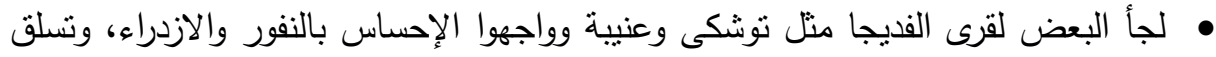
البعض الجبال والصخور ، وأثند ما عاناه النوبيون هو الإحساس بعدم الاكتراث بهم.

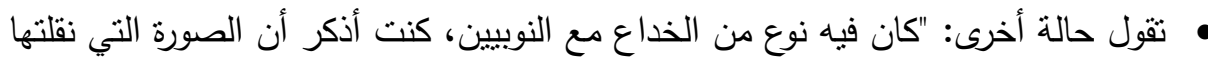

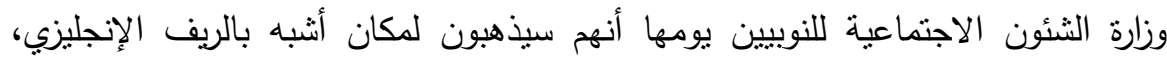
مازالت أتذكر البيوت النوبية بعد التهجير كانت بدون مياه، والتعويضات كانت هزيلة جداً،

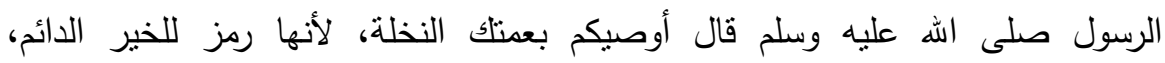

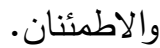

دراسة كونوروروسنبلود(7 99 ( )): عنوان الدراسة: "دافعية الانتماء في كل تجربةمقارنة نظرية" أهداف الاراسة : هدفت الدراسة التعرف على دافعية الانتماء في كل تجربة .

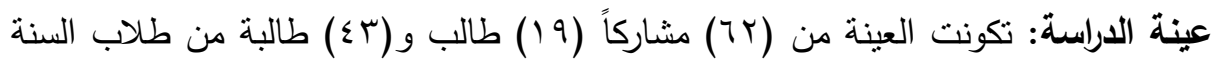
الثالثة من قسم علم النفس الاجتماعي بجامعة فيكتوريا. نتائج الدراسة: نم بحث اثتان من المفاهيم المتضمنة في دافعية الانتماء في التجارب

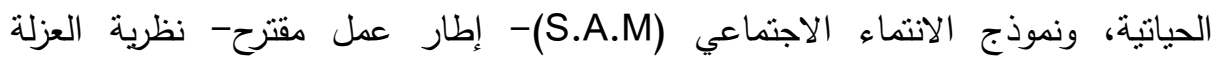

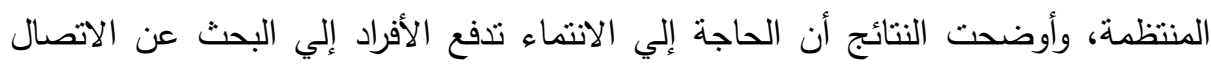
الاجتماعي في أوقات ما وعن الوحدة في أوقات أخرى. 


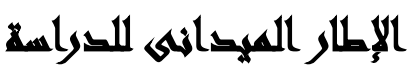

أولاً: المحددات المنهجية للاراسة الميدانية: تتضمن المحددات المنهجية تحديد نوع الدراسة والمنهج المستخدم وأدوات جمع البيانات وتحليلها وتحديد العينات وأسلوب اختبارها

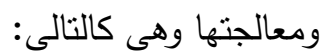
نوع الدراسة والمنهج المستخدم: تدخل هذه الدراسة فى نطاق الدراسات الوصفية لأنها أنسب الدراسات ملائمة لطبيعة الظاهرة المدروسة. أدوات جمع البيانات:

أ-استمارة استيبيان: بالنسبة لأداة الإسنتيان المطبقة على عينة النوبيين نم تصميم الأداة وفقآ

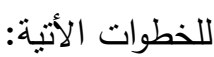
1 - قام الباحثون بيناء الصورة الأولية للأداة معتمدآ فى ذلك على الإطار النظرى والدراسات

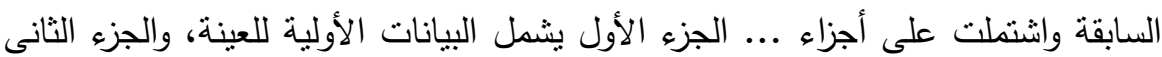
يشمل محاور الاستمارة ( المشكلات الاجتماعية، والمشكلات الفيزيقية ) والجزء الثالث

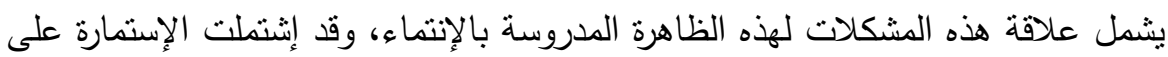

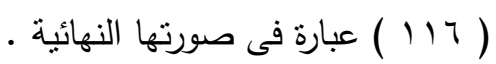

r- وبعد عرض الاستمارة على السادة المحكمين من أساتذة علم التربية والاجتماع والبيئة والخدمة الاجتماعية من جامعة عين شمس والجامعات الأخرى، وموافقتهم عليها بعد إجراء

$$
\text { التعيلات، تم تقنين استمارة الاستبيان وتطبيقها. }
$$

صدق وثيات الأداة:

أولاً : صدق الاداة : حيث قام الباحثون فى اطارمراعاة صدق الأداة بعرض الاستبيان على عدد من الاساتذة المحكمين بهدف تقييمها وتوضيح رؤيتهم فى تحقيق الأداة لأهداف الدراسة، وقد قرر السادة المحكمين أن العبارات الموجودة بالإستبيان ترتبط إرتباطآ بموضوع الدراسة، 
ثناتباً: الثـــات: قام الباحثون باختبار مبلئى لأداة البحث للتأكد من ثبات الأداة على مجموعة

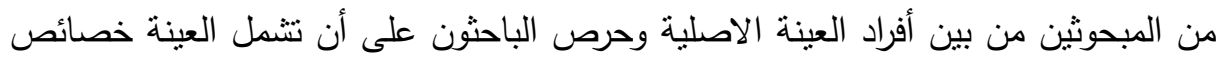

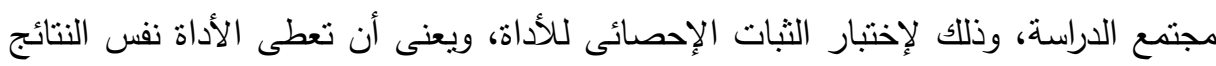
إذا أعيد تطبيقها أكثر من مرة تحت نفس الظروف، ويمكن تقديره بإعادة التطبيق أو التجزئة

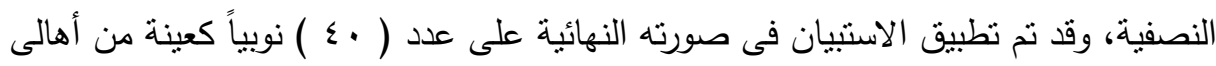

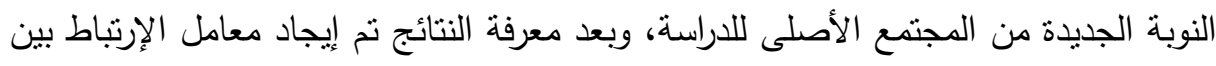

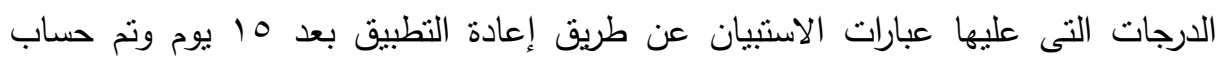

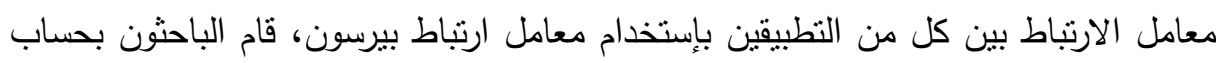

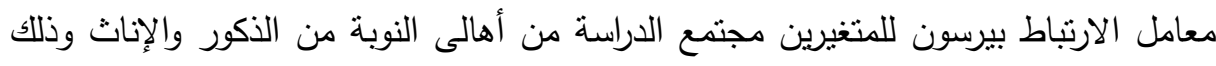

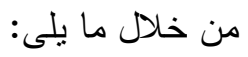
المرحلة الأولى: بالنسبة لأهالى النوبة الذكور ( Tلح، . ) وبالنسبة لأهالى النوبة من الإناث

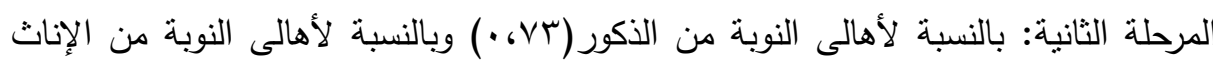

وكانت الغالبية العظمى من الاستجابات مطابقة للاستبيان الاصلى، وقد أدى ذلك كله إلى الاطمئنان لسلامة أداة البحث وفقآ لدواعى الثبات والصدق التهات المنهجيين وطبقآ للقواعد العلمية المعمول والمطبقة فى هذا، وبين ذلك مدى امكانية الاعتمادية على نتائج قائمة

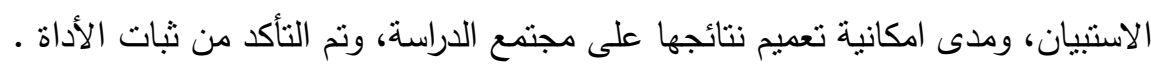

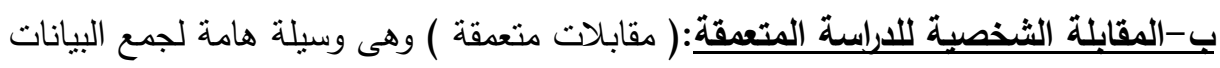
والمعلومات عن موضوع الدراسة وهو المشكلات الاجتماعية والفيزيقية لأهالى النوبة وعلاقتها بالإنتماء، حيث المقابلة وجهاً لوجه لسبر أغوار المبحوثين، هذا وقد تم الإستعانة باستمارة

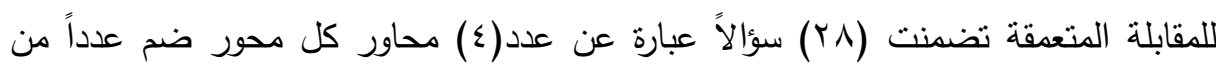
الأسئلة عن أراء المبحوثين فى المغنة 


$$
\text { ץ- با - ما المشكلات الاجتماعية لأهالى النوبة ؟ }
$$

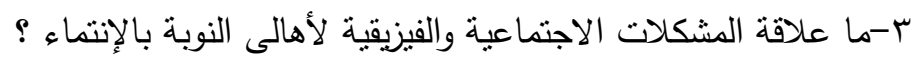

$$
\text { ع - وما المقترحات لتقوية هذا الإنتماء وتفعيله؟ }
$$

وقد شملت المقابلات الثخصية للاراسة المتعقة عدد (· r ) من أهالى من الذكور

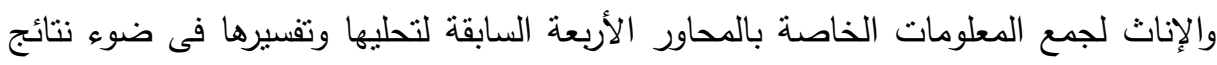
هذه المقابلات.

صدق وثبات أداة المقابلة المتعقة: هذا وقد تم عمل صدق وثبات لهذه الأداة بنفس الإجراءات التى تمت بصدق وثبات أداة الاستبيان وبنفس الخطوات المذكور سابقاً، وفيها تم

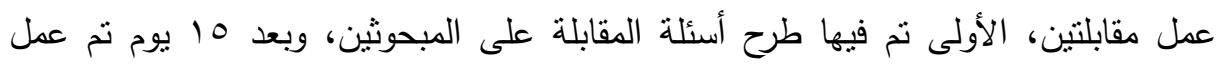

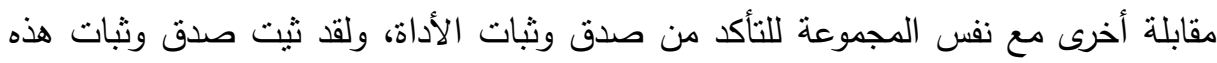
الأداة من خلال مقارنة الإجابات فى كل من المفابلة الأولى والثانية، وكانت النتيجة كالتالى ولى لئى فى كل من المقابلتين: الدقابلة الأولى: بالنسبة لأهالى النوبة الذكور ( V^، ، ) ) وبالنسبة لأهالى النوبة من الإناث المقابلة الثانية: بالنسبة لأهالى النوبة من الذكور (V0، ·) وبالنسبة لأهالى النوبة من الإناث

أداة الملاحظة كأدوات لجمع البيانات: والملاحظة إحدى أدوات جمع البيانات من مجتمع البحث حيث إنه عن طريق الملاحظة المقصودة وغير المقصودة يمكن جمع بيانات لا يمكن

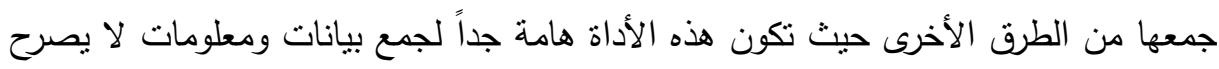

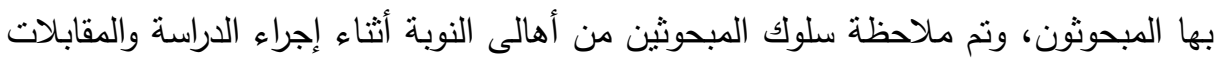

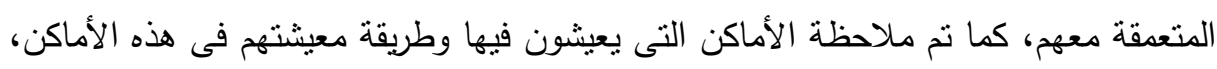
وذلك أثثاء الدراسة الميدانية من خلال الملاحظة بالمعايشة، وعمل ( دليل للملاحظة) وتم عمل صدق وثبات لتلك الأداة بنفس طريقة استمارة الاستبيان والمقابلات المتعدقة وتسجيل

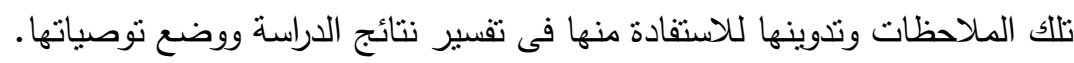


علماً بأن العينة التى تم ملاحظتها شملت حوالى ( · r ) من أهالى النوبة من الذكور والإناث طبقاً للخطة. صدق وثبات أداة الملاحظة : هذا وقد نم عمل صدق وثبات لهذه الأداة بنفس الإجراءات التى تمت بصدق وثبات أداة الانتبيان والمقابلة المتعقة وبنفس الخطوات الدذكور سابقاً، وفيها تم زيارة الأماكن التى تمت فيها الملاحظة مرنين، الأولى نم فيها ملاحظة ما سيتم ملاحظته

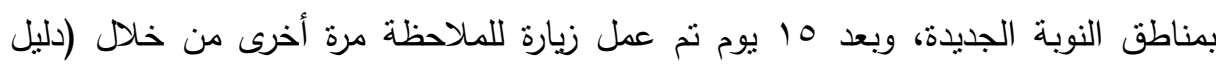

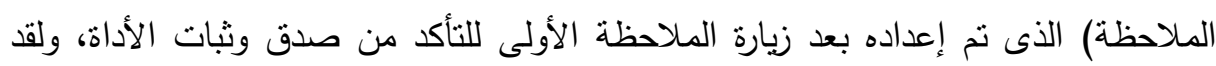

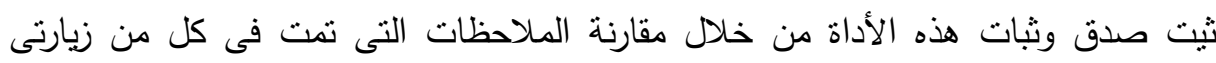

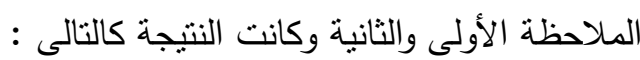
الملاحظة الأولى : بالنسبة لأهالى النوبة الذكور ( Vo ، . ) وبالنسبة لأهالى النوبة من الإناث الملاحظة الثانية : بالنسبة لأهالى النوبة من الذكور (V0، · ) وبالنسبة لأهالى النوبة من الإناث ** واستعان الباحثون ببعض الأساليب الإحصائية منها اختبار .testT، والتكرارات والنسب ومعاملات الإرتباط للتعرف على البيانات ذات الدلالة الاحصائية من خلال استخدام برنامج الإحصائى.spss ه-مجالات الدراسة : تتحدد مجالات الدراسة الحالية فى التالى: أ- المجال الجغرافي: ويقصد بالمجال الجغرافي هو النطاق المكاني لإجراء الدراسة وفى هذه

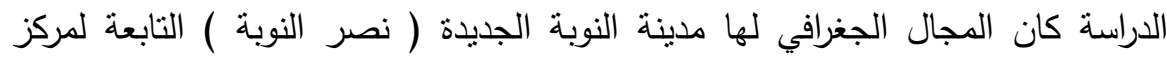

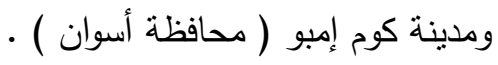

ب- المجال البشرى: وهم النوبيين من أهالى النوبة الجديدة من مختلف الأعمار والفئات

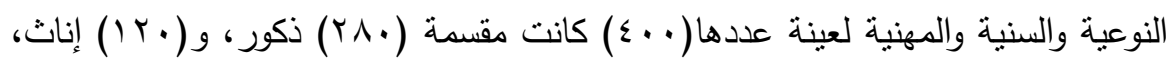

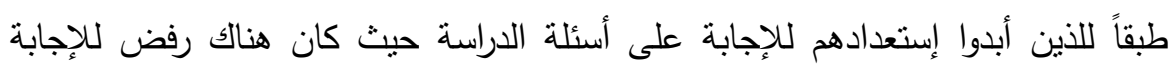

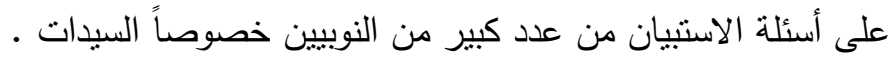


ج- المجال الزمني: استغرقت الدراسة الميدانية قرابة الثلاثة أثنهر، ابتداء من شهر فبراير

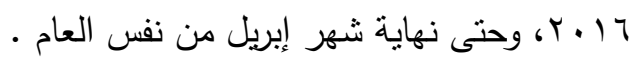

ثانياً: الإجراءات المنهجية للاراسة الميدانية : وتتشل هذه الإجراءات مجتمع البحث والزيارات الاسنطلاعية، تحديد حجم العينة، وجمع البيانات، والتحليل الإحصائى، ويمكننا فى هذا الإطار الحديث عن هذه الإجراءات تقصيلاً كالتالى: 1-مجتمع البحث: لقد حاول الباحثون تجميع قدر من البيانات المتصلة بالمشكلات

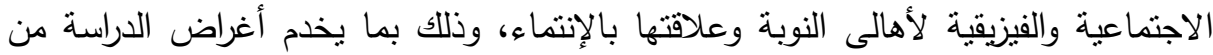

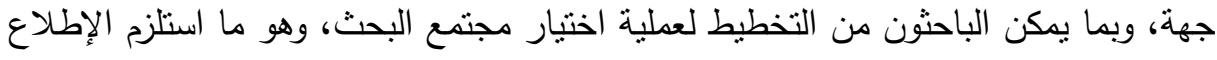

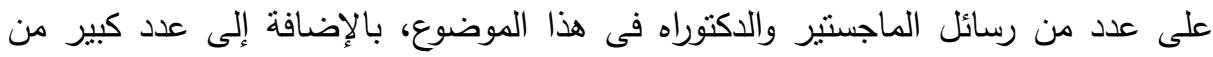
الدراسات والبحوث المعنية بدراسة مشكلات أهالى النوبة، وقد حدد الباحثون العينة الخاصة

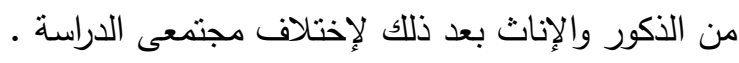
الزيارات الاستطلاعية: لقد قام الباحثون بعدد من الزيارات الاستطلاعية لمجتع البحث وذلك دلإن

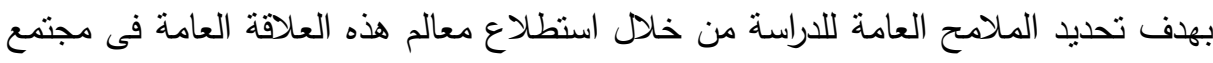
البحث والتعرف على العوامل المؤثرة فيها حتى يمكن إزالة الفجوة غالباً ما تحدث بين الباحثين

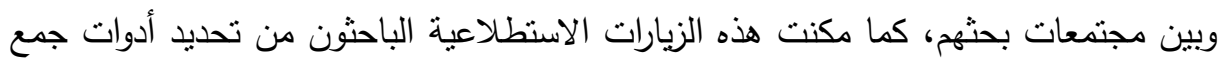

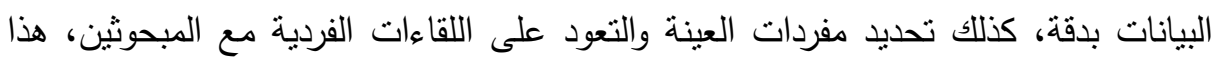
وقد مكنت الزيارات الاستطلاعية التى قام بها الباحثون فى مجتمع البحث من تغطية هذه

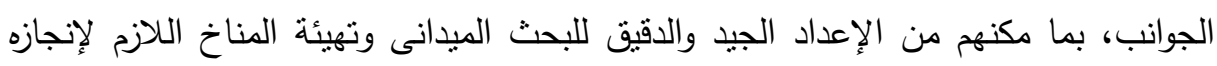

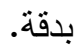
r-حجم العينة: تم اختيار عينة البحث بطريقة عشوائية من أهالى النوبة من الذكور والإناث،

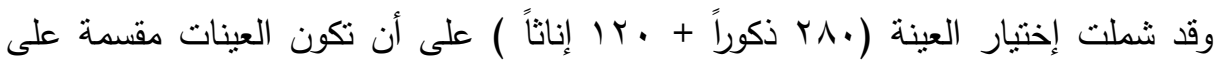
المناطق النوبية الجديدة، لهحاولة التوصل حول مدى الإختلاف بين رؤى الأهالى لهذه

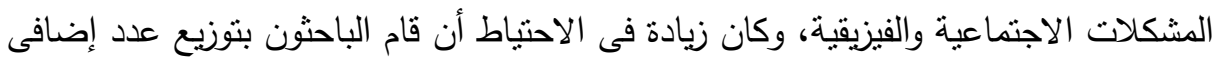

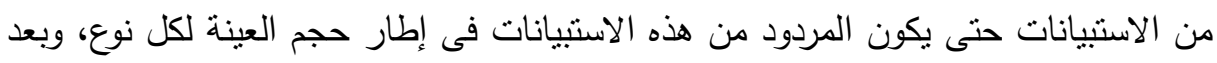

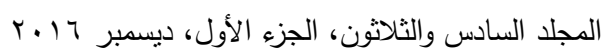


توزيع الاستمارات تم استبعاد ما يقرب من \1 استمارة وذلك لعدم جدية المبحوثين، ومن ثم تم

$$
\begin{aligned}
& \text { النطبيق الإحصائى على ( . ــ) مبحوث. } \\
& \text { r-جمع البيانات: }
\end{aligned}
$$

- تم طبع ( · بـ) نسخة من استمارة الاستبيان فى صورته النهائية الثاملة لكافة البيانات

$$
\text { المحققة لأغراض الدراسة. }
$$

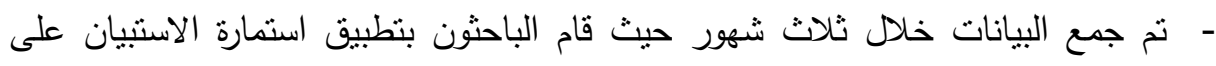
أفراد مجتمع البحث من اجل التعرف على أبرز وأهم المشكلات الاجتماعية والفيزيقية لأهالى النوبة وعلاقتها بالإنتماء.

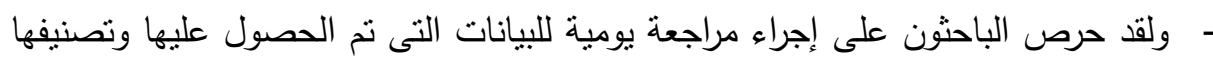

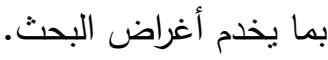

؟-التحليل الإحصائى: لقد تمت عملية تحليل البيانات بعد الإنتهاء من تطبيق استمارة

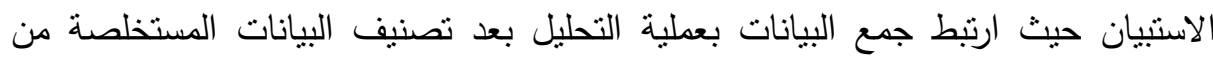

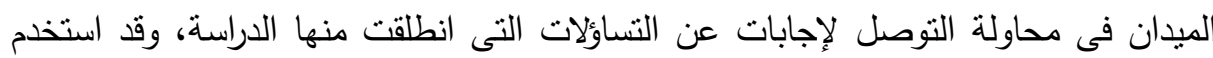
الباحثون المعالجة الإحصائية فى إطارين:

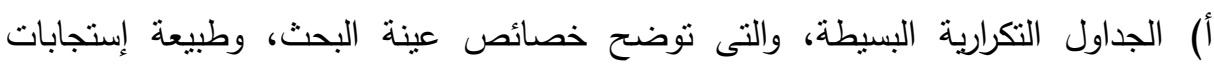
العينة.

ب) اختبار (كاب) لتوضيح الدلالات الإحصائية بين المتغيرات وحجم ونسبة العلاقات بينها،

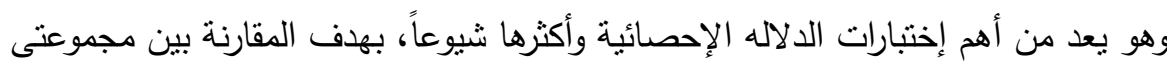
الذكور والإناث للوقوف على مدى اختلاف او اتساق رؤاهما حول المشكلات بينهما، كم تم استخدام المتوسطات المختلفة ومعمل إرتباط بيرسون • 
خصائص عينة الاراسة:

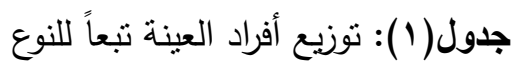

\begin{tabular}{|c|c|c|}
\hline النسبة: \% & التكرار & الإجابة \\
\hline$\% \vee v$ & rA. & ذكور \\
\hline \% r. & $\pi$. & إناث \\
\hline$\% \quad \ldots$ & $\varepsilon \ldots$ & الإججمالى \\
\hline
\end{tabular}

تفسير وتحليل الجدول: يشير الجدول رقم (1) إلى توزيع أفراد العينة الإجمالية لمجتمع

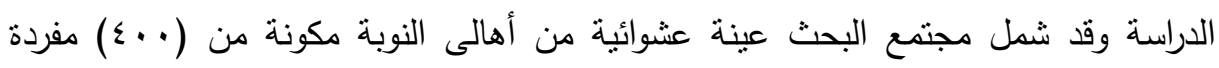

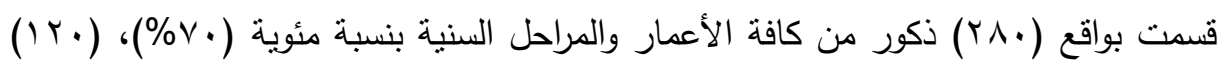
إناث من كافة الأعمار والمراحل السنية بنسبة مئوية (•r\%) بحيث تمثل هذه العينة قدر

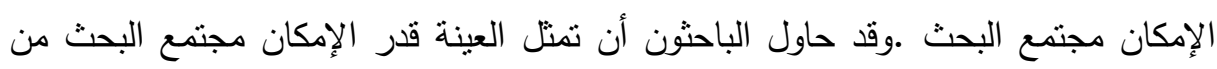

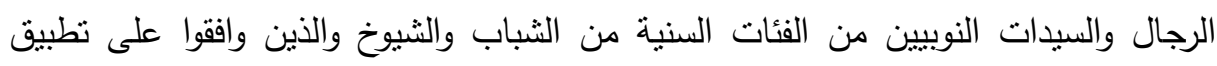

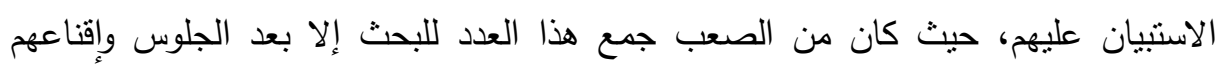

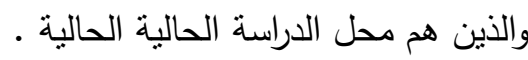
وصف وتحليل الجداول الاحصائية لإستخراج النتائج

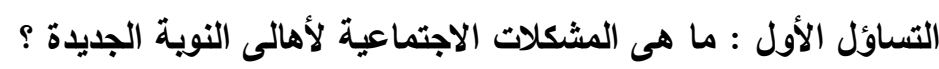

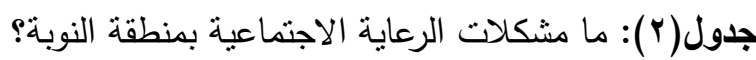

\begin{tabular}{|c|c|c|c|c|c|c|c|c|c|c|c|c|c|c|c|}
\hline \multicolumn{8}{|c|}{ اناث } & \multicolumn{7}{|c|}{ ذكور } & \multirow{3}{*}{ العبـارة } \\
\hline \multirow[b]{2}{*}{ كاr } & \multirow{2}{*}{ المريح } & \multicolumn{2}{|c|}{ إلى حـ ما } & \multicolumn{2}{|c|}{ نع } & \multicolumn{2}{|c|}{$\gamma$} & \multirow{2}{*}{ المترجح } & \multicolumn{2}{|c|}{ إلى حل ما } & \multicolumn{2}{|c|}{ نعم } & \multicolumn{2}{|c|}{$\gamma$} & \\
\hline & & $\%$ & 3 & $\%$ & 3 & & $a$ & & $\%$ & $a$ & $\%$ & 3 & $\%$ & 3 & \\
\hline$r 01, \Lambda_{0}$ & . & . & & . & & $1 .$. & ir. & $v_{\imath}, \wedge$ & $17, \varepsilon$ & $\varepsilon 7$ & $\uparrow, \uparrow$ & 198 & 10 & \& & ضدم وجند \\
\hline ג r r & or, & $r v, o$ & \&0 & $r v, 0$ & \&0 & ro & $r$. & $1 \ldots$ & . & . & $1 \ldots$ & ra. & & & 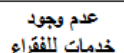 \\
\hline $19 \mathrm{~V}, 91$ & or, 1 & $r \cdot \wedge$ & ro & $\approx 1, v$ & $\circ$. & $r v, 0$ & $\varepsilon_{0}$ & $1 \ldots$ & . & . & $1 \ldots$ & rA. & & & خدمات لأنوبة \\
\hline$r \varepsilon v, \psi \varepsilon$ & $r \cdot, \Lambda_{0}$ & $u, v$ & $v \xi$ & . & & $\psi_{\Lambda}, \psi$ & 4 & $q \mathrm{v}, \mathrm{V}$ & 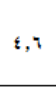 & $1 \%$ & $q_{0, \mathfrak{z}}$ & riv & & & خدمات للألمومية \\
\hline & סור, דו & VT, & AA & . & & $r_{7, v}$ & rr & $9 \wedge, \xi$ & $r, r$ & 9 & 97,1 & rvi & & & خدمات للمبرة \\
\hline$\varepsilon \ldots$ & $\psi_{0, \xi}$ & $v \cdot, \wedge$ & 10 & . & & $r a, r$ & ro & $1 \ldots$ & . & . & $1 \ldots$ & rA. & & & عدم رعاعلية \\
\hline
\end{tabular}

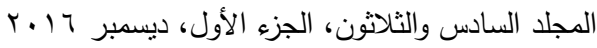


وصف وتحليل الجدول: يتبين من وصف جدول (r) أن هناك فروقاً ذات دلالة إحصائية بين الذكور والإناث النوبيين للتساؤل الأول عن المشكلات الاجتماعية لأهالى النوبة للعبارات

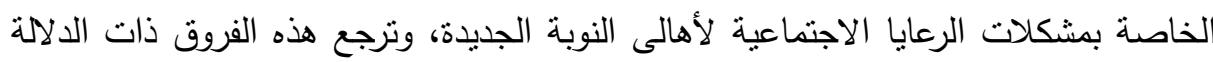

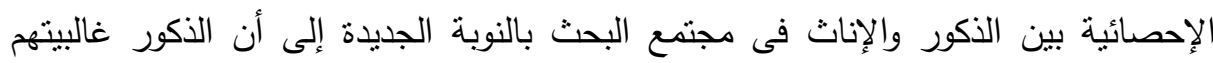

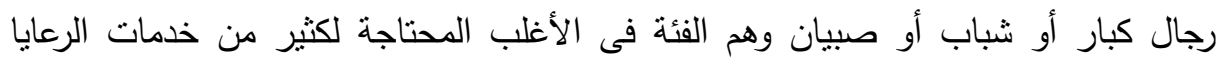

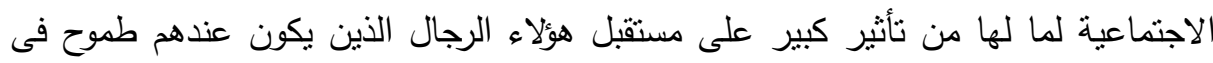

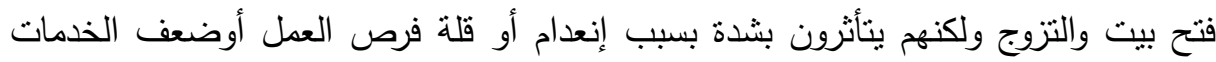
المقدمة لتلك الفئة مما يجعلها عرضة لكثير من المشاكل مع آسرهم ومن حولهم، أما بالنسبة للإناث فإن الفروق بينهم وبين الذكور ترجع إلى شعور الإناث وغالبيتهم من السيدات

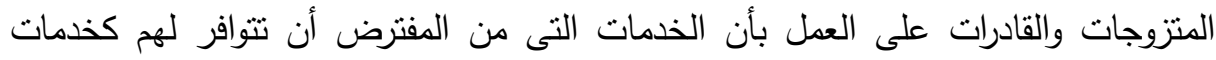

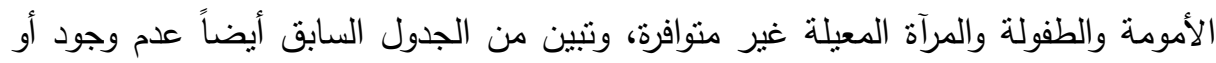

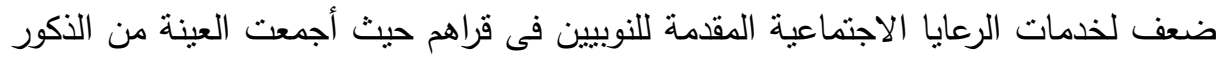
والإناث على عدم وجود أو ضعف خدمات الضمان الاجنماعى والخدمات المقدمة للفقراء وذوى الاحتياجات الخاصة وضعف خدمات الامومة والطفولة والمرأة المعيلة ورعاية المتعطلين، ويتبين من وصف الجدول السابق أن هناك حاجة ماسة للنوبيين لتوفير هذه ودها الخدمات الحياتية الضرورية لهم حتى تخفف من المشاكل الحياتية لهم وتزيد من إرتباطهم

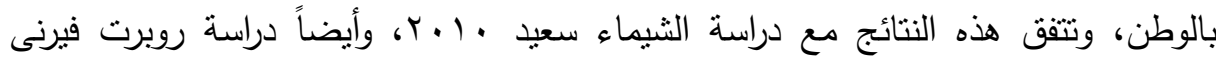


حاتم عبد المنعم أحمد وآخرون

التساؤل الثانى: ما هى المشكلات الفيزيقية لأهالى النوية الجديدة: جدول(r): إجابات أفراد العينة على نساؤلات المشكلات الفيزيقية

\begin{tabular}{|c|c|c|c|c|c|c|c|c|c|c|c|c|c|c|c|}
\hline \multicolumn{8}{|c|}{ اناث } & \multicolumn{7}{|c|}{ ذكور } & \multirow{3}{*}{ العبــــارة } \\
\hline \multirow{2}{*}{ r s } & \multirow{2}{*}{ المرتوجت } & \multicolumn{2}{|c|}{ إلى حـ ما } & \multicolumn{2}{|c|}{ نع2 } & \multicolumn{2}{|c|}{$\gamma$} & \multirow{2}{*}{ المرتوجت } & \multicolumn{2}{|c|}{ إلى حل ما } & \multicolumn{2}{|c|}{ نعم } & \multicolumn{2}{|c|}{$y$} & \\
\hline & & $\%$ & 9 & $\%$ & 9 & $\%$ & 9 & & $\%$ & 3 & $\%$ & 9 & $\%$ & 9 & \\
\hline$r \vee q, 7$ & . & & & & & $1 \ldots$ & $1 r$. & $v_{1}, \varepsilon_{0}$ & $r$ & 97 & $0\}$ & lor & 11,8 & rr & 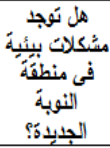 \\
\hline 109,1 & . & & & & & $1 \ldots$ & ir. & $\leqslant \mathrm{V}, \wedge \bullet$ & $\{r, 1$ & 111 & $r, \wedge$ & $v_{0}$ & r & AV & 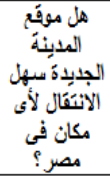 \\
\hline 70,1 & . & & & & & $1 \ldots$ & $1 r$. & $1 ., 197$ & $r$. & 01 & 19,7 & 00 & $7, \varepsilon$ & 179 & 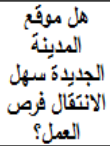 \\
\hline$r .0, v$ & $1 \cdot, \mathfrak{s}$ & $r \cdot, \Lambda$ & Yo & & & $V q, r$ & 90 & Ar,. O & rr,q & 90 & 17,1 & 110 & & & خلال فصل المبل \\
\hline$r r q, r$ & YA, & $01, \mathrm{~V}$ & $i 1$ & & & $\{r, r$ & or & דו, & \urcorner,$\wedge$ & 19 & $9 r, r$ & ודו & & & خلال فلّل المناخ \\
\hline
\end{tabular}

وصف وتحليل الجدول: يتبين من وصف جدول (ץ) أن هناك فروقاً ذات دلالة إحصائية بين

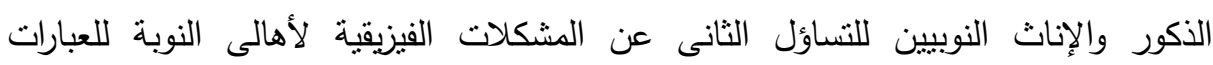
الخاصة بمشكلات البيئة لأهالى النوبة الجديدة، وترجع هذه الفروق ذات الدلالة الإحصائية

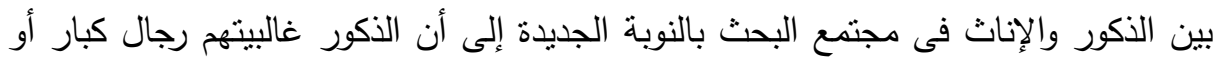

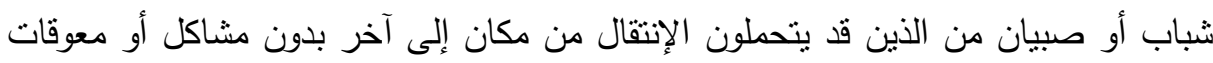

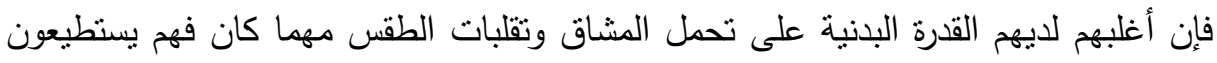
العمل والتجول بدون مشاكل، أما الإناث فإنهم وإن اسنطاعوا تحمل الأعمال المنزلية الثاقة لإنة

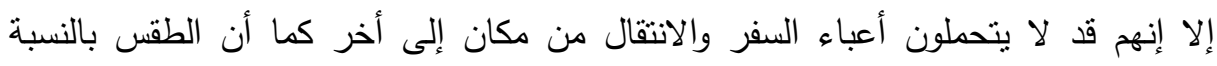
للنساء النوبيات مهماً حيث يتحملون الطقس لدرجات معينة، ويتبين من وصف وتحلين اعليل الجدول

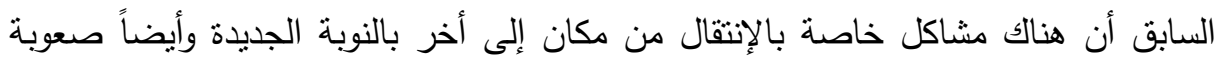

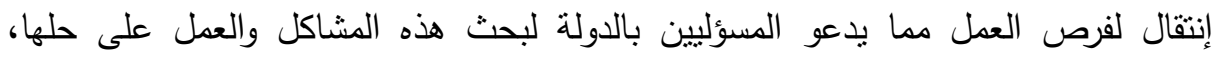

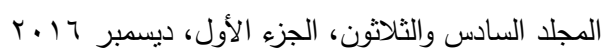


ويتبين أيضاً أن النوبيين من الذكور والإناث يتقبلون الأحوال المناخية صيفاً وشتاءً ويصفونها

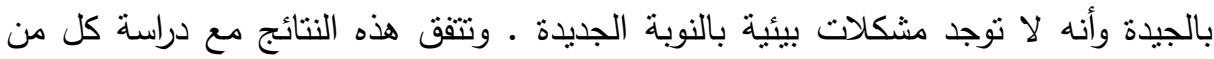

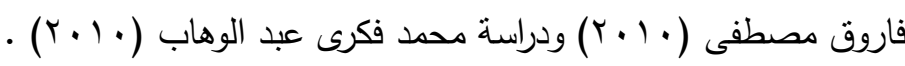
التساؤل الثالث والرابع: ما علاقة هذه المشكلات الاجتماعية والفيزيقية بالانتماء للوطن

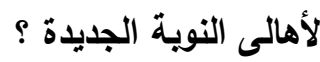
جدول( ؛): إجابات أفراد العينة على تناؤلات الإنتماء للوطن

\begin{tabular}{|c|c|c|c|c|c|c|c|c|c|c|c|c|c|c|c|}
\hline \multicolumn{8}{|c|}{ اناث } & \multicolumn{7}{|c|}{ ذكور } & \multirow{3}{*}{ العبــــارة } \\
\hline \multirow[b]{2}{*}{ Sا r } & \multirow{2}{*}{ المرئوسج } & \multicolumn{2}{|c|}{ إلى حـ ما } & \multicolumn{2}{|c|}{ نعم } & \multicolumn{2}{|c|}{$\gamma$} & \multirow{2}{*}{ المئوسج } & \multicolumn{2}{|c|}{ إلى حـ ما } & \multicolumn{2}{|c|}{ نعم } & \multicolumn{2}{|c|}{$y$} & \\
\hline & & $\%$ & 9 & $\%$ & 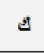 & & 3 & & $\%$ & 9 & $\%$ & 9 & $\%$ & 9 & \\
\hline זva, & . & & & & & $1 \ldots$ & $i r$. & $\vee \backslash, \Lambda$ & צו זr & Q & $\therefore$ & 10\{ & & & 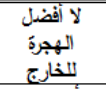 \\
\hline דוז & or,o & ro & $\& r$ & ro & $\& r$ & $r$. & 4 & $1 \ldots$ & & & $1 .$. & ra. & & & 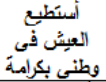 \\
\hline $101, r$ & ri, & $r+, O$ & rv & $01, v$ & ir & $r_{0,1}$ & ri & $1 \ldots$ & & & $1 \ldots$ & ra. & & & أحافظ علَّة \\
\hline $\mid v\{, \varepsilon \mid$ & or, & $i v, 0$ & $r$ & $\varepsilon v, 0$ & ov & ro & $\varepsilon$ & $1 \ldots$ & & & $1 \ldots$ & ra. & & & ألباس أحفظ عالزب \\
\hline irv,r & $i v, 0$ & 10 & 11 & $\because$ & ve & ro & r. & $1 \ldots$ & & & $1 \ldots$ & ra. & & & أحافظ على المعادات \\
\hline$m_{\uparrow \Lambda, O}$ & $1 \ldots$ & & & $1 \ldots$ & ir. & & & $\wedge 1,1$ & 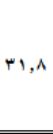 & 19 & $10, v$ & $1 \wedge \xi$ & $r, 0$ & $v$ & 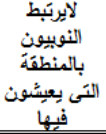 \\
\hline
\end{tabular}

وصف تفسير وتحليل الجدول: يتبين من وصف جدول (ع) أن هنالك فروقاً ذات دلالة إحصائية بين الذكور والإناث النوبيين للنساؤل الخاص بالإنتماء لأهالى النوبة للعبارات

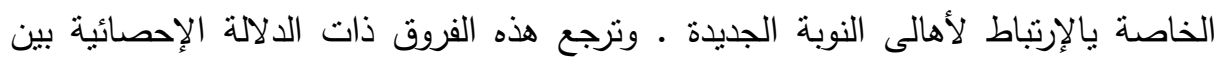

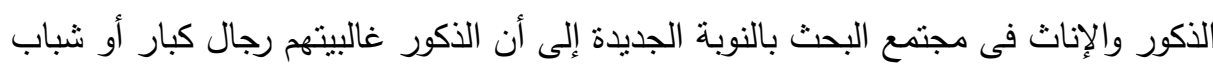

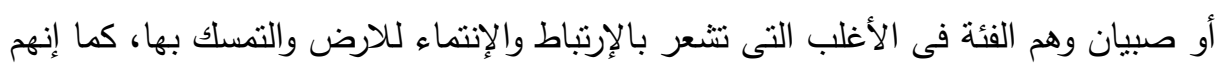

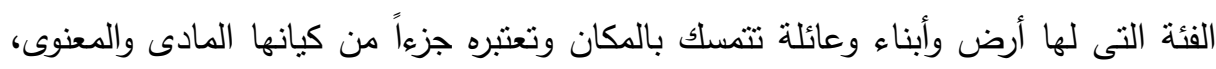

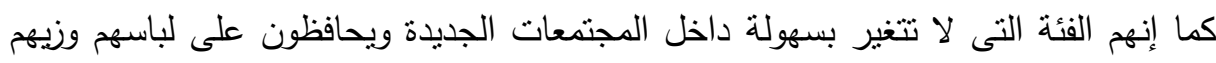

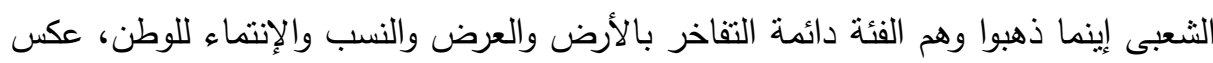
140

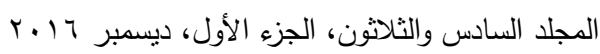


النساء الذين هم مع الرجال إينما ذهبوا فهم فى الأغلب يكونون تابعيين للرجال فالتمسك

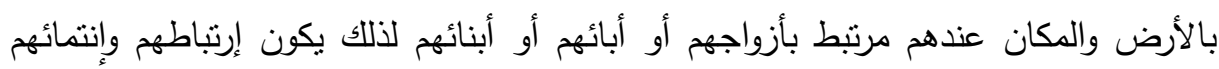

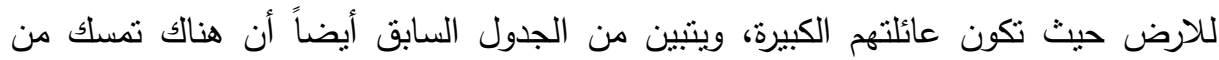

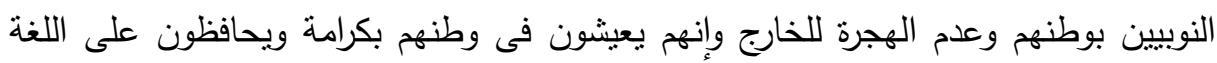
الرسمية للوطن والزى واللباس الرسمى والعادات والتقاليد، وهذه نقاط جيدة وطئن أظهرتها الدراسة حيث الإيجابيات التى يمكن استغلالها للإتفاق مع النوبيين لحل مشاكلهم، وتنين من الجدول

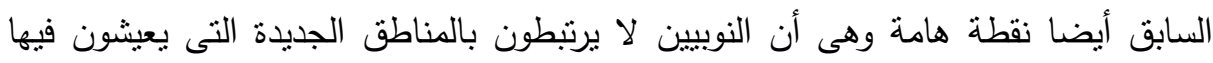

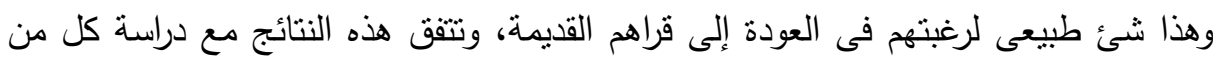

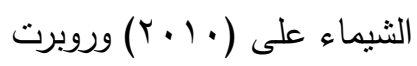

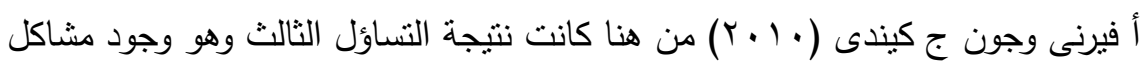

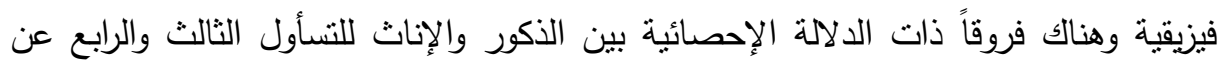

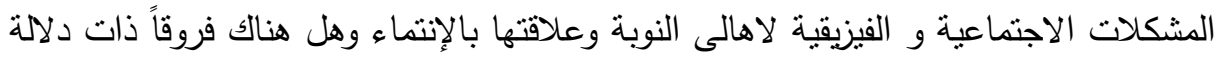
إحصائية بين الذكور والإناث لهذا التساؤل. جدول(ه): العلاقة الارتباطية بين عينة الدراسة والإجابات على ابعاد الدراسة

\begin{tabular}{|c|c|c|}
\hline إجمالى العينة & & الأسباب الاجتماعية \\
\hline$(* *) \cdot, 0$ \% & معامل إرتباط بيرسون & \multirow{2}{*}{ المشكلات الاجتماعية والاقتصادية } \\
\hline$\cdot, \cdots$, & الدلالة المعنوية & \\
\hline$(* *) \cdot, 099$ & معامل إرتباط بيرسون & \multirow{2}{*}{ المرافق بمنطقة النوبة الجديدة } \\
\hline$\cdot, \cdots 1$ & الدلالة المعنوبة & \\
\hline$(* *) \cdot, \Sigma \vee \cdot$ & معامل إرتباط بيرسون & \multirow{2}{*}{ المشكلات الفيزيقية } \\
\hline$\cdot, \cdots 1$ & الدلالة المعنوية & \\
\hline$(* *) \cdot \sum \wedge r$ & معامل إرتباط بيرسون & \multirow[t]{2}{*}{ الإنتماء بين سكان النوبة } \\
\hline$\cdot, \cdots 1$ & الدلالة المعنوية & \\
\hline$(* *) \cdot, 011$ & معامل إرتباط بيرسون & \multirow[t]{2}{*}{ اجمالى المقياس } \\
\hline$\cdot, \cdots$, & الدلالة المعنوية & \\
\hline
\end{tabular}


وصف تفسير وتحليل الجدول: يتضح من جدول (0) أنه توجد هناك علاقات إرتباطية ذات دلالة معنوية العلاقة الارتباطية بين عينة الدراسة وإجابات ابعاد الدراسة للمتغيرات التالية

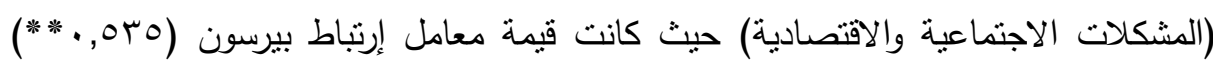
بدلالة معنوية (1 .., (·) و (المرافق بمنطقة النوبة الجديدة) حيث كانت قيمة إرتباط معامل بيرسون (099, • ***) بدلالة معنوية (1 (., . •) و (المشكلات الفيزيقية) حيث كانت قيمة إرتباط

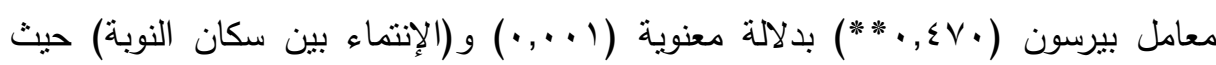

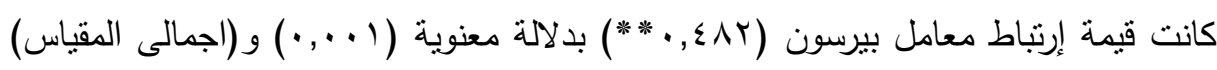

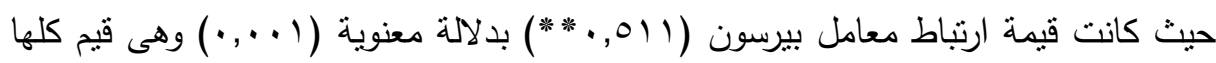
دالة معنوياً على وجود علاقة إرتباطية بين عينة الدراسة وإجابات ابعاد الدراسة للمتغيرات عاليه.

\section{نمانيج الصوراهة}

• أظهرت نتائج الدراسة أن هنالك شكاوى كبيرة من النوبيين من انخفاض الدخل أو عدم كفايته. • أنشارت نتائج الدراسة أن من أسباب إنخفاض الدخل أو عدم كفايته هى عدم وجود التربة الصالحة للزراعة فى المنطقة الجديدة مما يحد من أرزاقهم بها.

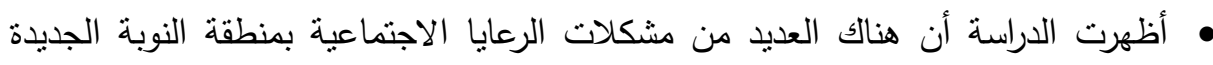

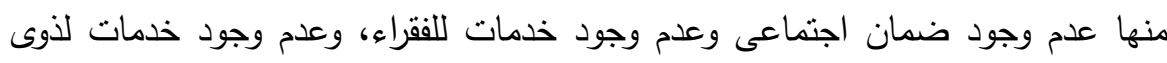
الإحتياجات الخاصة، وضعف وجود خدمات للأمومة والطفولة وعدم وجود خدمات للمرأة المعيلة. • بينت الدراسة أن هناك مشكلات بالعمل نواجه الأسر النوبية منها: قلة فرص العمل وضعف الأجور وكساد المشروعات . • بينت الدراسة أن هناك ضعف في تأهيل الثباب لسوق العمل. 
• أظهرت الدراسة أن هناك العديد من مشكلات التعليم بمنطقة النوبة الجديدة منها عدم إستيعاب المدارس للطلاب وإزدحام الفصول وسوء حالة المدارس وسوء المرافق وإهمال المدرسين والإدارة والمعاملة غير اللائقة من قبل بعض المدرسين والأساتذة .

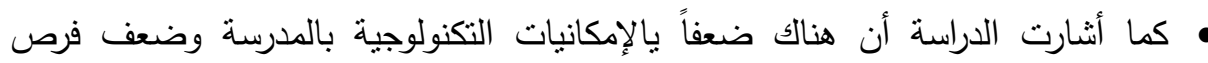
التعليم العالى ويكاد يكون منعدماً للفتيات .

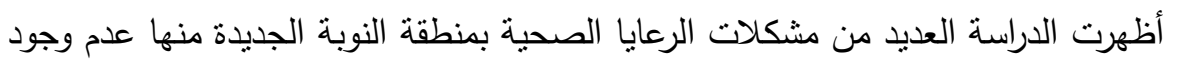
مستتفيات أو سوء حالة المستشفيات الموجودة والبعيدة عنهم، وسوء حالة الوحدات الصحية . هبيت الدراسة أن من مشكلات الرعايا الصحية بمنطقة النوبة الجديدة تتمثل فى ندرة الأطباء والهيئات المعاونة لهم وعدم وجود أدوية أو عدم كفايتها وعدم وجود سيارات إسعاف كافية . ألماء • أنثارت الدراسة أن تطعيم الأطفال متوافر بمنطقة النوبة الجدبدة . أثارت الدراسة إلى أن هناك العديد من المشكلات الأمنية فى منطقة النوبة الجديدة منها، ضعف النواجد الأمنى وزيادة عدد البلطجية وزيادة السرقات وزيادة العنف وسوء مناء معاملة الثرطة وإنتشار المخدرات. بينت الدراسة أن هناك العديد من مشكلات المرافق بمنطقة النوبة الجديدة منها، ضعف

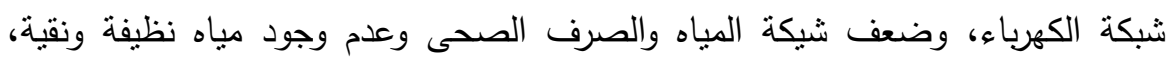
وعدم وجود سيارات إطفاء.

هأظهرت الدراسة أن هناك العديد من المشكلات الفيزيقية فى منطقة النوبة الجديدة منها أن المكان الجديد صعب الإنتقال منه لاى مكان فى مصر ، كما أن هناك صعوبة فى إنتقال فرص العمل للنوبة الجديدة . بينت الدراسة أن أهالى النوبة يرون أن المناخ مناسب خلاد فصلي الصيف والشتاء.

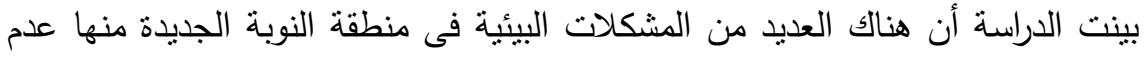
صلاحية الأرض الزراعية للزراعة وعدم ملائمة المساكن بيئياً من حيث الإتساع والتهوية لئه

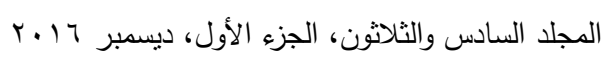


أظهرت الدراسة أن هناك العديد من المشكلات الخاصة بالمسكن منها ضيق المسكن وعدم وجود مصادر جيدة للتهوية، كما أن هناك عدم خصوصية للمسكن والكثير من

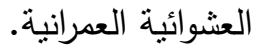

وأثنارت الدراسة إلى عدم وجود ثأثثرات مناخية على سكان النوبة الجديدة. أظهرت الدراسة حب النوبيين للوطن والإنتساب إليه حيث اعرب الغالبية العظمى من

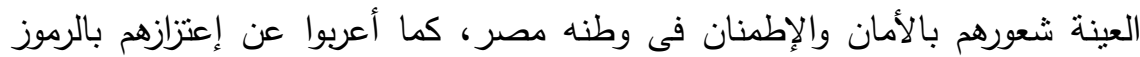
المصرية وتقديرها، كما أعربوا عن شعورهم بالفخر كونهم مصريون، وأعربت الغالبية العظى من العينة أن بلدهم مصر أجمل بلد فى الدنبا. بينت الدراسة أن هناك حالة إرتباط بين النوبيين والوطن ظهر من خلال إختياراتهم على النى لإنى أنهم لا يفضلون الهجرة من الوطن، وأعربوا على إنهم يعيشون فى الوطن بكرامة، كما لها لهن

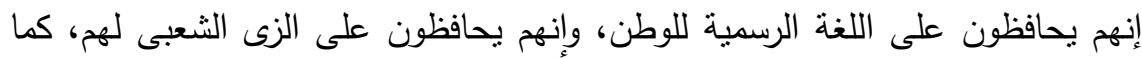
إنهم يحافظون على العادات والثقاليد المصرية ولا يخرجون عليها. بينت الدراسة أن النوبيون يحصلون على حقوقهم السياسية كاملة ويهتمون بالمشاركة

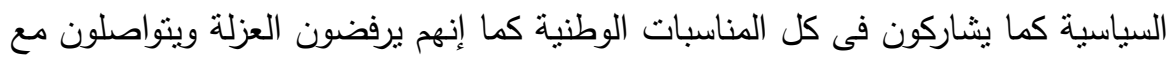
الأخرين من أبناء الوطن كما يقرون بأن الخدمات التعليمية تتوافر بشكل مناسب، كما لتها إنهم يهتمون بالمشاركة مع إخوانهم فى كافة المناسبات الاجتماعية.

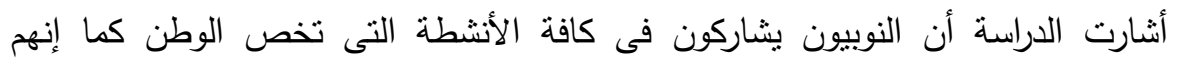

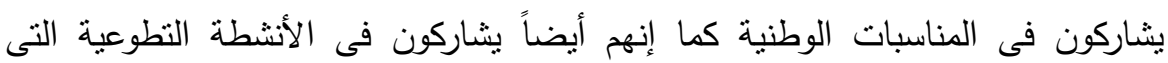

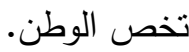
ويرى النوبيون كما بينت الدراسة أن مشاركتهم فى الإنتخابات تؤثر فى صنع القرار كما أقروا أن بإستطاعتهم التعبير عن أرائهم بحرية مطلقة. بينت الدراسة أن النوبيون يفضلون الجنسية المصرية على الجنسيات الأجنبية، ويرون أنهم إنه

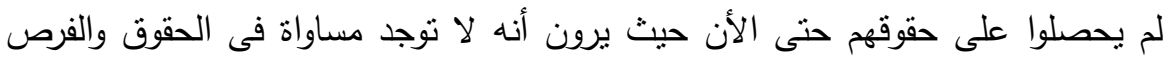

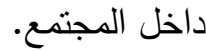


•بينت الدراسة أن هناك شعور بين النوبيون بأنهم تعرضوا لظلم تاريخى من الأنظمة المصرية، كما يرون أنهم يتعرضون لمعاملة منصفة من الثرطة المصرية.

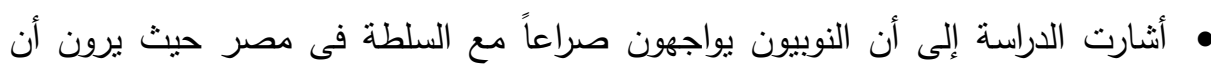
التهجير مثل ظلم تاريخى لهم. • بينت الدراسة أن النوبيون يرون أنه لا توجد تفرقة داخل المجتمع المصرى على أساس العرق.

\section{تروسيامس الصواسما}

توجيه نظر المسؤليين بالحكومة المصرية بضرورة عمل مشروعات خاصة بمنطقة النوبة تستوعب أهالى النوبة وذلك لتوفير فرص عمل دائمة لهم تعمل على توفير مصادر دخل

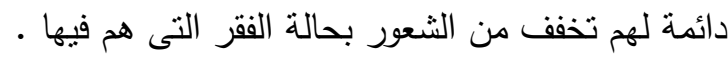
• أن على الحكومة أن تضع أهالى النوبة ضمن خطة المليون ونصف فدان وذللك بتوفير

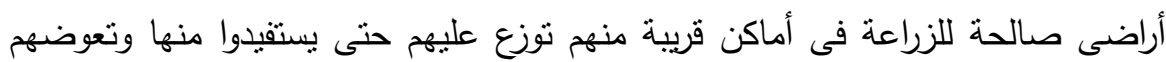

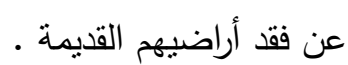

•حث المشاكل المادية للنوبيون ومحاولة تعويضهم حيث بتعرض أغلب النوبيون لضيق فى لـ مستوى المعيشة داخل القرى بالنوبة الجديدة .

• توفير معاشات للضمان الاجتماعى لكل أهالى النوبة تخفف من وطأة الحالة المادية الصعبة التى يعيشون فيها، وتوفير خدمات اجتماعية ومشروعات للأسر المنتجة للنوبيون تعوضهم عن ضعف الاخول لديهم، كما إنه يجب نوفير خدمات لذوى الإحتياجات

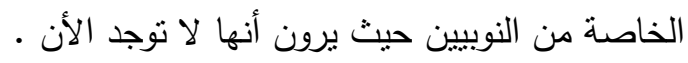

• توفير خدمات خاصة بالأمومة والطفولة، وتوفير مشروعات خاصة بالمرأة النوبية المعيلة .

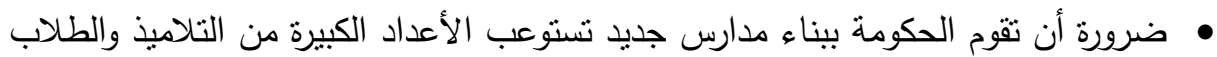
النوبيون وتخفف من التكدس الموجود حالياً داخل المدارس فى النوبة الجديدة، خصوصاً لمرحلة التعليم الأساسى التى يوجد بها تكدس كبير جداً بمختلف مدارس النوبة الجديدة . 
• كما إنه لابد من وجود خطط لتجديد المدارس القديمة تخفف من سوء حالتها الحالية سواء

$$
\text { من ناحية المبانى أو المرافق الموجودة بها. }
$$

هما أن على مديرية التعليم المسئولة عن مدارس النوبيين أن توجه الإهتمام لحسن معاملة

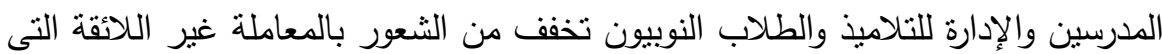

$$
\text { يشعرون بها حالياً. }
$$

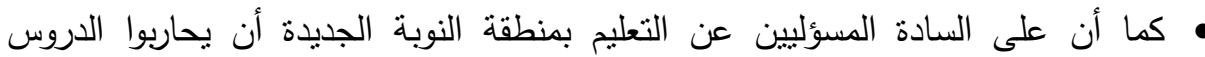
الخصوصية لما لها من أثنار سيئة على أولياء الأمور والطلاب، وتوفير المدرسيين

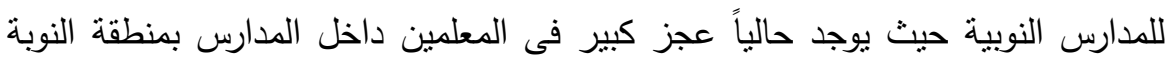

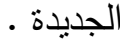

• العمل على توفير الرعايا الصحية من بناء للمستشفيات بمختلف المناطق النوبية حيث أن

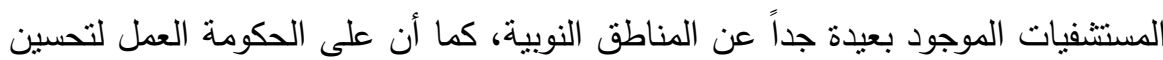

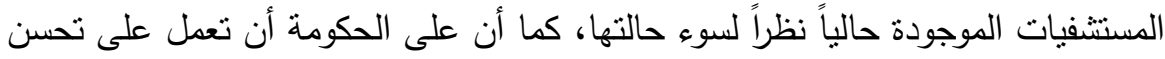
الوحدات الصحية الموجودة بالمناطق النوبية حيث إن خدماتها التى تقدمها ضعيفة جداً . • كما أن على الجهات المسئولة بالأمن توفير نقاط شرطة تعمل على الحد من البلطجة

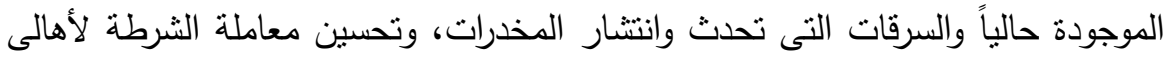

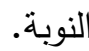
ضرورة عمل مشروعات خدمية لتحسن شبكات الخدمات من مياه وكهرباء وصرف صحى نظراً لسوء حالتها الأن أو عدم وجودها ببعض المناطق بالنوبة الجديدة، كما أنه ليس هناك سيارات إطفاء ويجب توفيرها حتى يشعر النوبيون بالإطئنان فى حالة لا قدر الهه نشوب حرائق بمنطقة النوبة الجديدة. النوبيون مرتبطون بمناطقهم القديمة لذا يسعى النوبيين إلى الرجوع إلى تلك المناطق

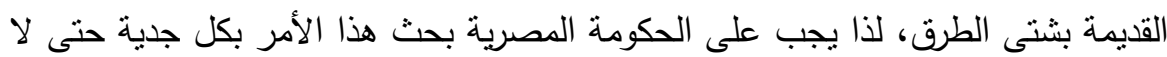
تتحول إلى مشكلة دولية حيث يسعى بعض من ليس عندهم وطنية إلى سكب البنزين على النار وتدويل قضية النوبة ليجعلونها ورقة ضغط على الدولة المصرية يستتزفون بها قدرات 
الدولة ومقدراتها لذا يجب تشكيل لجنة برلمانية لبحث هذه الأمور وحل مشكلات النوبيون حتى لا يستغلها بعض المغرضين لتخريب مصر . • كما أن على الحكومة المصرية تخصيص كوته برلمانية لأبناء النوبة لعرض مشاكلهم

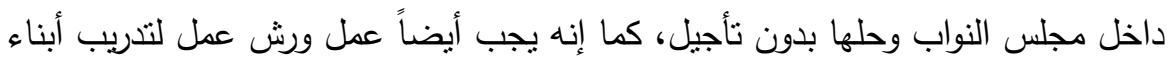
النوبة على كيفية المشاركة فى الإنتخابات من الترشح والإنتخاب لتوعيتهم بحقوقهم. • عمل طلبات إحاطة داخل مجلس النواب لبحث مشاكل النوبيون والعمل على حلها.

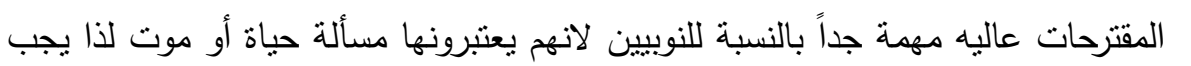

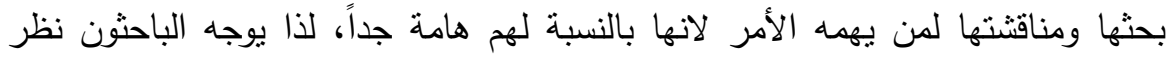

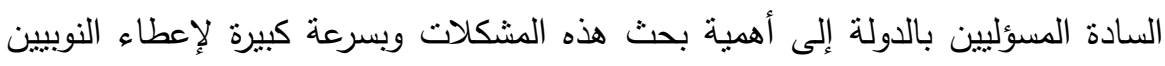

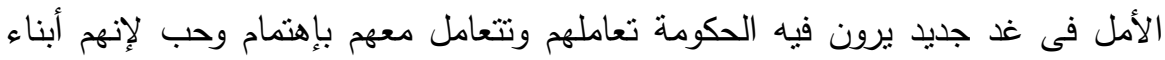
وطن يحبونه ولا يرضون بغيره. بحوث مقترحة للبحث وللاراسة: هـ النوبة الجديدة والنوبة القديمة ما مدى الفروق من جميع المجالات، ولماذا يفضلها النوبيون

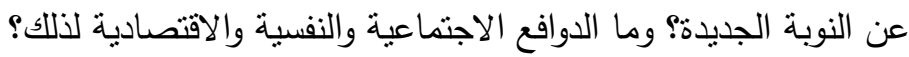
• أبناء النوبة الجديدة ومدى إرتباطهم النفسى والاجتماعى بالنوبة الجديدة. • النوبة الجديدة لماذا لا يحبها النوبيون.

•النوبة القديمة ومدى إستعدادها لعودة محتملة لأبناء النوبة إليها مرة أخرى.

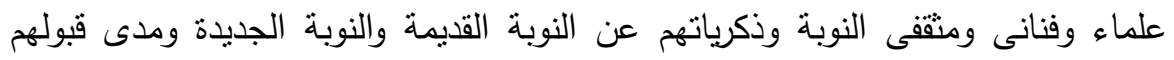
لمسألة العودة إلى النوبة القديمة وهجر النوبة الجديدة.

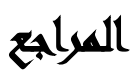

أحمد زكى بدوى(Y Y (1)): معجم مصطلحات العلوم الاجتماعية، بيروت، مكتبة لبنان، ص .17 عاطف محمد فؤاد(910 ()): الصفوة المصرية، قضاياها وانتماءاتها، القاهرة، دار المعارف،، ص E

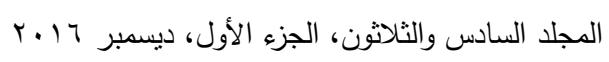




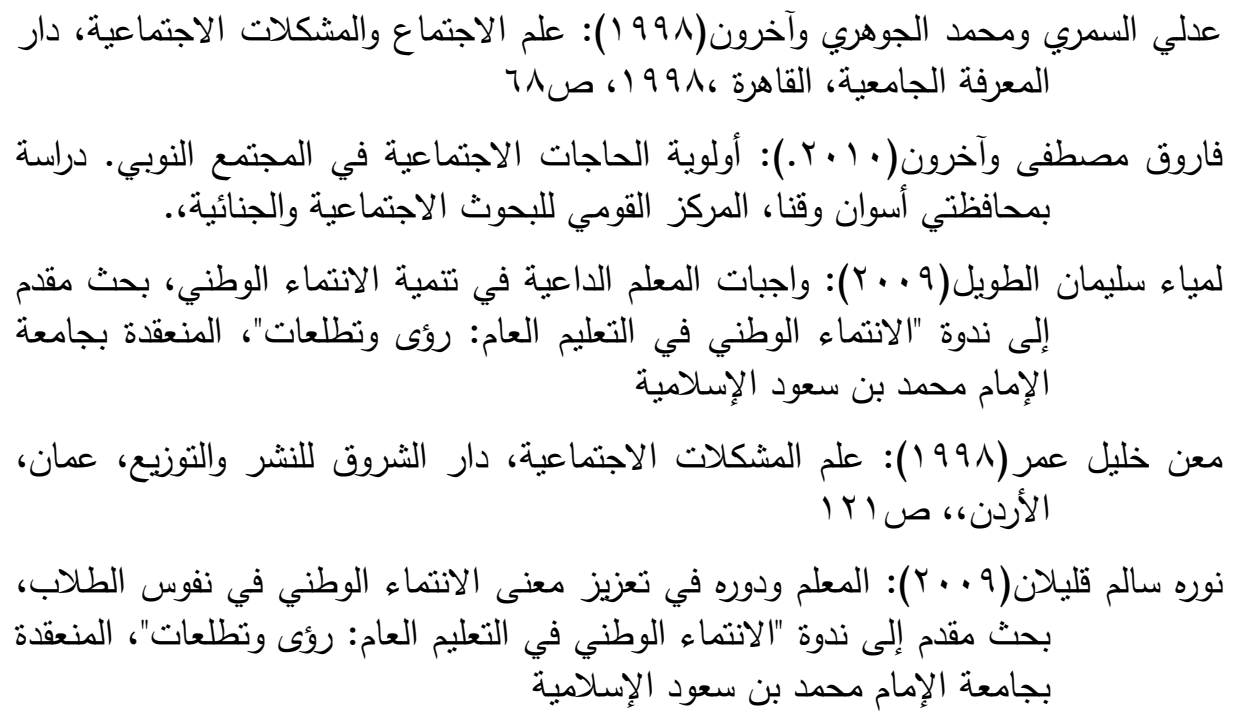

English, H.B. \& English A.C. A Comprehensive Dictionary of Psychological and Psychoanalytical Terns, New York, Longmans, 1958, p. 64.

Levet - Jones, Tracy ; Higgins, Isabel; Lathleen, Judith \& McMillan, Margaret. The duration of clinical placements: A key influence on nursing students' experience of belongingness. Journal of Advanced Nursing, V 26 (2), 8-9., 2009.

Walsh, Shari; White, Katherine \& Young, Ross, Phone connection: A qualitative exploration of how belongingness and social identification relate to mobile phone use amongst Australian youth. Journal of Community \& Applied Social Psychology,2009, V 19, 225-240. p 226. 


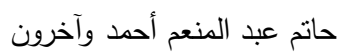

\title{
SOCIAL AND PHYSICAL PROBLEMS OF NUBBA PEOPLE AND THEIR RELATION TO AFFILIATION \\ A FIELD STUDY BETWEEN VARIOUS DIVERGENT \\ SOCIAL CLASSES
}

[6]

\begin{abstract}
Ahmed, H. A. ${ }^{(1)}$; Ahmed, G. S. ${ }^{(2)}$ and Abd El Aziz, Amaal. M.
1) Institute of Environmental Studies and Research, Ain Shams University. 2) Institute of Postgraduate Childhood Studies, Ain Shams University.
\end{abstract}

\begin{abstract}
This study purpose is to explore the social as well as the physical problems Nubba people are suffering from and their relation to affiliation. The field study is administered among various social classes. The sample consists of (400) persons of Nubba from different classes, divided into (280 males - 120 females). This study belongs to the qualitative (descriptive) type of studies using the social survey with random sample. The study also belongs to the analytical case study as a tool for collecting data from research population, belonging as well to the in-depth study of cases experienced these incidents. The researcher uses a questionnaire form, observation, and personal interview as study instruments, counting as well on some statistical approaches, for instance, T.test, frequencies, percentages, and coefficient correlations. The study show significant statistical differences exist between Nubian males and females concerning the various issues associated with Nubian people and community. Study results indicate the following:

- A great ratio of Nubians complains insufficient and low income.

- Results indicate that a reason of low income is the non-arable land and soil for cultivation in the new zone which restrict their seeking of earning of bread.

- Results also indicate that Nubians use different approaches for meeting poor income such as working more than one job, travelling

$$
\text { المجلد السادس والثناثون، الجزء الأول، ديسمبر } 1 \text {. } 1 \text {. }
$$


abroad for work, obtaining aids, rationalizing expenses and consumption, and living in debt.

- Results show that social care in the New Nubba is suffering from shortness in social guarantee, lack of services proposed to the poor, lack of services presented to those with special needs, shortness of services of motherhood and childhood, and lack of services for household woman.

- Results indicate that Nubians prefer Egyptian nationality to other foreign nationalities; yet, they think they haven't got their rights until now, so, they suffer inequality of rights and opportunities.

- Results indicate that Nubians were exposed to historical injustice and unfairness from all Egyptian systems.

- Results also indicate that Nubians are encountering a conflict with authority, as they think that dislodgment has been unfair historically and that their problems should be resolved with government and authority as fast as can. 